\title{
Hydrogen and copper isotope analysis of turquoise by SIMS: Calibration and matrix effects
}

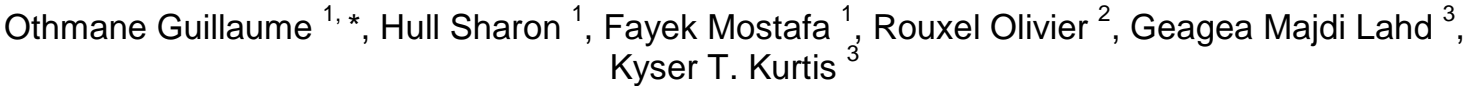

${ }^{1}$ Dept. of Geological Sciences, University of Manitoba, Winnipeg, MB, Canada R3T 2 N2

${ }^{2}$ IFREMER, Centre de Brest, Plouzané, 29280, France

${ }^{3}$ Dept. of Geological Sciences, Queen's University, Kingston, ON, Canada K7L 3 N6

* Corresponding author : Guillaume Othmane, tel.: + 12044747178 ; fax: + 12044747623 ;

email address : othmaneg@cc.umanitoba.ca

\begin{abstract}
:
The hydrogen isotope system is used extensively to provide information on the genesis of minerals (e.g., source of fluids and mechanisms of precipitation). The copper isotopic system is less well understood, but has the potential to provide valuable insight on mineral precipitation, particularly supergene $\mathrm{Cu}$-rich minerals. Here we present a rapid and precise method for measuring hydrogen and copper isotopes in semi-precious gem-quality turquoise $(\mathrm{Cu}(\mathrm{Al}, \mathrm{Fe} 3+) 6(\mathrm{PO} 4) 4(\mathrm{OH}) 8 \cdot 4 \mathrm{H} 2 \mathrm{O})$ by secondary ion mass spectrometry (SIMS). The suitability of standards for instrumental mass fractionation (IMF) calibration was assessed by external precision of SIMS measurements for each standard (2-4\%o for $\delta$ DIMF and $0.2-0.4 \%$ for $\delta 65 \mathrm{CuIMF})$. IMF in turquoise was correlated with $\mathrm{H}$ and $\mathrm{Fe}$ contents for $\mathrm{D} / \mathrm{H}$ measurements and $\mathrm{Fe}$ content for $65 \mathrm{Cu} / 63 \mathrm{Cu}$ measurements. Based on these correlations, IMF can be corrected to enable $\delta \mathrm{D}$ and $\delta 65 \mathrm{Cu}$ analyses by SIMS with accuracies of $\pm 5 \%$ and $\pm 0.5 \%$, respectively. The precision and accuracy of SIMS thus rivals those of other mass spectrometric methods for $\mathrm{H}$ and $\mathrm{Cu}$ isotopes and demonstrates the potential of SIMS applications in identifying gemstones provenance and understanding the genesis of turquoise deposits.
\end{abstract}

\section{Highlights}

- We developed a method for measuring $\mathrm{H}$ and $\mathrm{Cu}$ isotopes in turquoise by SIMS. $>$ IMF in turquoise is correlated with $\mathrm{H}$ and $\mathrm{Fe}$ contents for $\mathrm{D} / \mathrm{H}$ measurements. IMF in turquoise is correlated with $\mathrm{Fe}$ content for ${ }^{65} \mathrm{Cu} /{ }^{63} \mathrm{Cu}$ measurements. $\delta \mathrm{D}$ and $\delta^{65} \mathrm{Cu}$ in turquoise can be measured by SIMS with precision of $\pm 5 \%$ ond $\pm 0.4 \%$, respectively. Applications of this method include determining gemstones provenance and understanding the genesis of turquoise deposits.

Keywords : turquoise, SIMS, copper isotopes, hydrogen isotopes, matrix effects 


\section{Introduction}

Isotope ratio mass spectrometry (IRMS) is the high-precision method for measuring isotopes ratios with applications in isotope geochemistry, geochronology and cosmochemistry (Ireland, 2013). Three types of mass spectrometers are mainly used for bulk isotopes analysis. Elements that can be easily introduced as gases, such as $\mathrm{H}$, are typically analyzed using gas source mass spectrometers. In contrast, other elements such as $\mathrm{Cu}$, are analyzed by thermal-ionization mass spectrometers (TIMS) (Walker et al., 1958) and more recently by multi-collector inductively coupled plasma mass spectrometers (MC-ICP-MS) (Maréchal et al., 1999). Although bulk isotopic analysis techniques frequently offer better precision and accuracy than in situ techniques, there are several analytical considerations. All traditional bulk isotopic analysis techniques are destructive, which can be problematic for (semi-) precious gemstones or archaeological artifacts analysis. In addition, some of these techniques require extensive sample processing prior to analysis. Sample preparation often involves chemical separation of the element of interest, which is time consuming and requires a large amount of material. In addition, Maréchal et al., 1999 and Maréchal and Albarède, 2002 showed that failure to achieve total $\mathrm{Cu}$ recovery from ion exchange columns prior to mass spectrometry analysis resulted in severe isotopic fractionation (up to $24 \%$ ). Other analytical considerations include the occurrence of mineral inclusions at the micron-scale in the sample studied, which may be incorporated in bulk analysis and produce erroneous values.

Laser ablation (LA) MC-ICP-MS techniques are now increasingly used to measure spatially resolved and high-precision copper isotope ratios (Graham et al., 2004; Ikehata et al., 2008; Li et al., 2010). Laser ablation techniques have many advantages compared with bulk techniques. Indeed isotopic ratios measurements 
using laser ablation require a smaller amount of sample and a much easier sample preparation procedure (i.e., without chemical extraction procedures), and can provide spatial distributions of isotopic composition.

Secondary ion mass spectrometry (SIMS) is a technique that was developed to provide in situ measurement of isotopic ratios with a spatial resolution on the scale of a few $\mu \mathrm{m}$. Despite its higher cost, the SIMS technique can potentially overcome the issues associated with the more destructive laser isotopic analysis methods, especially for (semi-) precious gemstones studies. SIMS is less destructive than laser ablation, especially in terms of spot size $(10 \mu \mathrm{m}$ for SIMS versus $>40 \mu \mathrm{m}$ or raster areas that are several 100's of $\mu \mathrm{m}$ for LA-ICP-MS to achieve the same level of precision) and penetration depth (0.5 to $1.0 \mathrm{~mm}$ for SIMS versus $>40 \mu \mathrm{m}$ for LA-ICP-MS) and is better suited to avoid sample impurities at the micron-scale. SIMS has been used for many studies in the earth sciences, including trace elements, light stable isotopes, geochronology and cosmochemistry (Fayek, 2009; MacRae, 1995; Reed, 1989), and in the cultural heritage (Darque-Ceretti and Aucouturier, 2004; Dowsett and Adriaens, 2004). For example, SIMS has been used to determine the provenance of gem minerals (Giuliani et al., 2000; Ludwig et al., 2011; Shabaga et al., 2010; Giuliani et al., 2000).

As with other mass spectrometers, during the measurement process by SIMS, an intrinsic mass dependent bias is introduced, which is referred to as instrumental mass fractionation (IMF) and typically favors the low mass isotope. IMF occurs at various analysis stages, including sputtering, ionization, extraction, transmission of the secondary ions through the mass spectrometer, and secondary ion detection. However, the greatest contributor to the IMF is the ionization process, which depends most strongly upon sample characteristics (i.e., chemical composition). This is 
referred to as compositionally dependent fractionation or "matrix effects" (e.g., Riciputi et al., 1998). Therefore, accurate isotopic SIMS analysis requires that IMF be corrected for by standardizing the IMF using mineral standards that are compositionally similar to the unknown. In the case of mineral solid solutions, standards spanning a wide compositional range are often necessary to accurately correct the IMF. Corrections using linear interpolations between only the two endmembers of one solid solution may indeed lead to large errors (e.g., Bell et al., 2009; Eiler et al., 1997; Page et al., 2010; Riciputi et al., 1998; Valley and Kita, 2009).

The aim of this study is to develop protocols for precise and accurate, in situ, microanalysis of hydrogen and copper isotopes in turquoise by SIMS. Turquoise is a semi-precious gem stone with a range of chemical compositions (e.g., turquoisechalcosiderite solid-solution series, $\mathrm{Cu}\left(\mathrm{Al}, \mathrm{Fe}^{3+}\right)_{6}\left(\mathrm{PO}_{4}\right)_{4}(\mathrm{OH})_{8} \cdot 4 \mathrm{H}_{2} \mathrm{O}$; Abdu et al., 2011; Foord and Taggart, 1998). Therefore, the development of standardization protocols for $\mathrm{D} / \mathrm{H}$ and ${ }^{65} \mathrm{Cu} /{ }^{63} \mathrm{Cu}$ measurements by SIMS over a wide range of turquoise compositions can provide a relatively non-destructive, valuable method for determining the provenance of this semi-precious gem mineral.

\section{Standards and cross-calibration}

\subsection{Samples}

Nine samples from turquoise deposits throughout the Southwestern United States were collected (Table 1). Turquoise samples purity was assessed by powder X-ray diffraction (XRD) and Fourier-transform infrared (FTIR) spectroscopy. Samples were crushed and sieved to the $<350$ mesh $(5-10 \mu \mathrm{m})$ size fraction prior to XRD analysis. 
Powder XRD measurements were performed with $\mathrm{Cu} \mathrm{K} \alpha$ radiation in Bragg-Brentano geometry on a Philips (PANalytical) PW1710 automated diffractometer. Data were processed using the MDI Jade+ software. FTIR spectra were collected in the transmission mode at room temperature, using a Bruker Tensor 27 FTIR spectrometer equipped with a KBr beam splitter and a DLATGS detector. Spectra over the range $400-4000 \mathrm{~cm}^{-1}$ were obtained by averaging 100 scans with a resolution of $4 \mathrm{~cm}^{-1}$. To record IR spectra, approximately $2 \mathrm{mg}$ of dried sample was gently ground with 200 $\mathrm{mg}$ of dried $\mathrm{KBr}$. The mixture was pressed at 10 tons $/ \mathrm{cm}^{2}$, oven-dried overnight to remove adsorbed water and pressed again to produce a $\mathrm{KBr}$ pellet. Baseline correction was done using the OPUS spectroscopic software (Bruker Optic GmbH).

2.2. Samples preparation for EPMA and SIMS analysis

For electron probe micro-analysis (EPMA) and SIMS analysis, $1 \mathrm{~mm}$ to $1 \mathrm{~cm}$ size pieces of turquoise were arranged in holes drilled in $25 \mathrm{~mm}$ diameter aluminium mounts. Buehler "Epoxide" epoxy resin was then poured in and allowed to harden overnight. The hardened epoxy mounts were then polished using various grit (6001200) SiC sandpaper and 1-15 $\mu \mathrm{m}$ diamond polishing compounds. The mounts were then washed with a dilute soap solution, ultrasonically cleaned in deionized water and ethanol, and placed in an oven at $60^{\circ} \mathrm{C}$ for 20 minutes to remove adsorbed water.

\subsection{EPMA}

Sample mounts were coated with a thin layer of carbon for conductivity. The major element concentrations of the turquoise standards were determined using a Cameca 
SX-100 electron microprobe at the University of Manitoba. Operating conditions were $15 \mathrm{keV}$ accelerating voltage, $20 \mathrm{nA}$ beam current, a beam size of $10 \mu \mathrm{m}$ and data acquisition in wavelength-dispersive spectrometry (WDS) mode. The following standards were used: albite $(\mathrm{Na})$, olivine $(\mathrm{Mg})$, andalusite $(\mathrm{Al})$, diopside $(\mathrm{Si}, \mathrm{Ca})$, apatite $(\mathrm{P})$, pyrite $(\mathrm{S})$, orthoclase $(\mathrm{K})$, titanite $(\mathrm{Ti})$, chromite $(\mathrm{Cr})$, fayalite $(\mathrm{Fe})$, chalcopyrite $(\mathrm{Cu})$, and gahnite $(\mathrm{Zn})$. Corresponding detection limits were on the order of 0.1 wt. $\% . \mathrm{H}_{2} \mathrm{O}$ contents were determined by difference.

\subsection{Standards composition}

Powder XRD and FTIR analyses showed that all samples mainly consist of turquoise, with traces of kaolinite for some samples (data not shown). The turquoise samples selected as standards ( 5 for the hydrogen study and 6 for the copper study) showed textural and chemical homogeneity (Table 2) and their chemical compositions (e.g., Fe content; Table 2) covered a wide range within the turquoise-chalcosiderite $\mathrm{Cu}\left(\mathrm{Al}, \mathrm{Fe}^{3+}\right)_{6}\left(\mathrm{PO}_{4}\right)_{4}(\mathrm{OH})_{8} \cdot 4 \mathrm{H}_{2} \mathrm{O}$ solid-solution series. Therefore, IMF that may be due to matrix effects could be quantified.

\subsection{Calibration of $\mathrm{D} / \mathrm{H}$ and ${ }^{65} \mathrm{Cu} /{ }^{63} \mathrm{Cu}$ values of standards}

Hydrogen isotopes ratios "true" values were measured by using a Finnigan MAT Delta 252 and a V.G. model 602 C gas source mass spectrometer. Water content of turquoise samples was obtained using the protocol of Kyser and O'Neil, 1984. Gas source mass spectrometer analyses were performed using a dual inlet system or a continuous flow method. In the dual inlet technique, the sample and standard gases 
were alternately introduced in the mass spectrometer ionization chamber. Prior to injection, the water was converted to $\mathrm{H}_{2}$ by reaction with uranium at $900^{\circ} \mathrm{C}$ following the method of Bigeleisen et al., 1952, as modified by Kyser and O'Neil, 1984. The dual-inlet method is very accurate because the sample and standard gases can be compared under essentially identical instrument conditions. In the continuous flow technique, the sample or the standard water was delivered via a He carrier gas stream to a furnace for reduction into $\mathrm{H}_{2}$ and subsequently to the ionization chamber. This method is usually faster than the dual-inlet method, avoiding off-line gas conversion steps, and requires less material (Sharp et al., 2001).

Copper isotopes ratios "true" values were measured using a multicollector inductively coupled plasma mass spectrometer (MC-ICP-MS) Neptune (Thermo Fisher Scientific) operating at the Pôle Spectrométrie Océan (IFREMER, Plouzané, France). The experimental protocol used was similar to that described by Rouxel et al., 2004; Maréchal et al., 1999; Chapman et al., 2006; Borrok et al., 2007; Palacios et al., 2011 and described below.

Turquoise samples were cleaned in distilled water and ethanol in an ultrasonic bath, dried and ground in an agate mortar. After a complete digestion step in concentrated $\mathrm{HF}-\mathrm{HNO}_{3}$ and $\mathrm{HCl}-\mathrm{HNO}_{3}$ mixture, bulk rock and $\mathrm{Cu}^{0}$ samples were dissolved in $2 \mathrm{~mL}$ of $6 \mathrm{~mol} / \mathrm{L}$ distilled $\mathrm{HCl}$ in a closed beaker on a hot plate. A precise volume of this solution was then purified using anion exchange chromatography in an $\mathrm{HCl}$ medium (distilled grade). A $5 \mathrm{~mL}$ column was loaded with $1.8 \mathrm{~mL}$ Bio-Rad AG1-X8 anion resin 200 - 400 mesh (chloride form) which was acid cleaned with 10 $\mathrm{mL}$ of $2 \mathrm{~mol} / \mathrm{L} \mathrm{HNO}_{3}, 10 \mathrm{~mL}$ of ultrapure water and $10 \mathrm{~mL}$ of $0.24 \mathrm{~mol} / \mathrm{L} \mathrm{HCl}$ and finally conditioned with $5 \mathrm{~mL}$ of $6 \mathrm{~mol} / \mathrm{L} \mathrm{HCl}$. Under these conditions, $\mathrm{Cu}$ (along with $\mathrm{Fe}$ ) was adsorbed onto the anionic resin while the sample matrix was eluted 
using $5 \mathrm{~mL}$ of $6 \mathrm{~mol} / \mathrm{L} \mathrm{HCl}$. Cu was then eluted (and separated from $\mathrm{Fe}$ ) with $50 \mathrm{~mL}$ of $6 \mathrm{~mol} / \mathrm{L} \mathrm{HCl}$, collected in a PTFE vial and evaporated to dryness. The residue was re-dissolved in $2-3 \mathrm{~mL}$ of $0.28 \mathrm{~mol} / \mathrm{L} \mathrm{HNO}_{3}$ and then further diluted to form a 0.1 to $0.5 \mathrm{ppm} \mathrm{Cu}$ solution ready for isotope analysis. Quantitative recovery of $\mathrm{Cu}$ through the entire chromatographic procedure was checked by calculating chemistry yield for each sample and also by checking $\mathrm{Cu}$ recovery in standard solution processes through chemistry.

Analyses of ${ }^{65} \mathrm{Cu} /{ }^{63} \mathrm{Cu}$ were carried out on the Neptune MC-ICP-MS operating at low resolution. The samples were introduced into the plasma using a double spray quartz chamber system (cyclonic and double pass) and a microconcentric PFA nebulizer operating at a flow rate of about $60 \mu \mathrm{L} \mathrm{min}{ }^{-1}$. Instrumental mass bias was corrected for using $\mathrm{Zn}$ isotopes as an internal standard and involves simultaneous measurement of a Zn standard solution (SRM 3168a Standard Solution). Also a standard bracketing approach, which normalizes the $\mathrm{Cu}$ isotope ratio to the average measured composition of a standard (SRM 976) was carried out before and after each sample. Standard deviation values (1SD) were calculated using 4 duplicate analysis.

\section{SIMS Methods}

A 200 A thick Au coat was sputter-deposited on the sample mount surfaces, prior to SIMS analysis using a Cameca IMS-7f ion microprobe at the University of Manitoba. The mounts were placed in stainless steel sample holders and the entire assembly was then placed in the SIMS sample lock and held at high vacuum for a minimum of eight hours prior to the start of analysis. Positive secondary ions were produced by an $\mathrm{O}^{-}$ beam with impact energy of $22.5 \mathrm{keV}$. The samples were analyzed using $40 \mathrm{nA},-12.5$ $\mathrm{kV} \mathrm{O}^{-}$primary beam focused on a $\sim 50 \mu \mathrm{m}$ spot. The largest contrast $(400 \mu \mathrm{m})$ and 
field $(1800 \mu \mathrm{m})$ apertures, in conjunction with $150 \mu \mathrm{m}$ image field and an energy bandpass of $\pm 25 \mathrm{eV}$, were used to maximize sensitivity. The secondary column high voltage was set to $10 \mathrm{kV}$.

\subsection{Isotopic measurements}

For $\mathrm{D} / \mathrm{H}$ isotopic measurements, the secondary ion mass spectrometer was operated at a mass resolution of $\sim 800$ to separate $\mathrm{D}^{+}$from $\mathrm{H}_{2}{ }^{+}$and sample voltage offset of $-50 \mathrm{~V}$, while maintaining the secondary column at $10 \mathrm{kV}$ to help minimize the $\mathrm{H}_{2}^{+}$peak (Liu et al., 2011). Each analysis ran for 50 cycles with a magnet settle time of $0.5 \mathrm{~s}$ between each mass and an analysis time of 1.04 seconds for $\mathrm{H}$ and $5.04 \mathrm{~s}$ for D. A Faraday cup detector was used for $\mathrm{H}$ and an electron multiplier was used for $\mathrm{D}$. The gain on the faraday cup relative to electron multiplier was calibrated before each analysis. Linear drift was corrected using mass $\mathrm{H}$.

For ${ }^{65} \mathrm{Cu} /{ }^{63} \mathrm{Cu}$ isotopic measurements, isobaric interferences were minimized by offsetting the sample high-voltage by $-50 \mathrm{~V}$. Each analysis ran for 60 cycles with a magnet settle time of 0.5 seconds between mass ${ }^{63} \mathrm{Cu}$ and ${ }^{65} \mathrm{Cu}$ and analysis time of $1.04 \mathrm{~s}$ for both ${ }^{63} \mathrm{Cu}$ and ${ }^{65} \mathrm{Cu}$. Both masses were measured using an electron multiplier with a dead time of $37 \mathrm{~ns}$.

The hydrogen and copper isotopic data are given in the Table 3 and 4, respectively. Isotopic data determined by solution GS-MS or MC-ICP-MS are presented using standard $\delta$-notation relative to the appropriate international standard, Vienna Standard Mean Ocean Water (V-SMOW) for hydrogen and NIST 976 for copper. The equation for calculating $\delta$ values in units of per mil (\%o) is:

$\delta_{\text {sample }}=\left(\mathrm{R}_{\text {sample }}-\mathrm{R}_{\text {std }}\right) / \mathrm{R}_{\text {std }} \times 1000$ 
where $\mathrm{R}_{\text {sample }}$ and $\mathrm{R}_{\text {std }}$ are the absolute ratios of $\mathrm{D} / \mathrm{H}$ or ${ }^{65} \mathrm{Cu} /{ }^{63} \mathrm{Cu}$ in the sample (turquoise) and the standard (V-SMOW or NIST 976), respectively. The absolute D/H ratio of V-SMOW is $155.76 \times 10^{-6}$ (Hagemann et al., 1970) and the absolute ${ }^{65} \mathrm{Cu} /{ }^{63} \mathrm{Cu}$ ratio of NIST 976 is $4.4563 \times 10^{-1}$ (Shields et al., 1964).

The isotope mass fractionation that occurs during SIMS analysis was calculated by using equation [2]:

$\alpha_{\text {SIMS }}=\mathrm{R}_{\text {SIMS }} / \mathrm{R}_{\text {actual }}$

where $\mathrm{R}_{\text {SIMS }}$ is the ratio measured by SIMS and $\mathrm{R}_{\text {actual }}$ is the accepted ratio measured by conventional techniques (GS-MS and MC-ICP-MS for hydrogen and copper isotopes, respectively).

The isotope mass fractionation that occurs during SIMS analysis $\left(\alpha_{\text {SIMS }}\right)$ can be converted into $\delta$ notation (in units of per mil) by using equation [3]:

$\delta \mathrm{R}_{\mathrm{IMF}}=\left[\mathrm{R}_{\text {SIMS }} / \mathrm{R}_{\text {actual }}-1\right] \times 1000=\left(\alpha_{\text {SIMS }}-1\right) \times 1000$

For each standard, at least 5 different spots $(n)$ were analyzed sequentially. The SB-1 standard was periodically analyzed within each session and no significant within run drift was observed. The internal precision is the average internal precision of the $n$ analysis spots. The external precision is calculated as the standard deviation of the $n$ analysis spots.

The internal precision of $\mathrm{D} / \mathrm{H}$ measurements was around $3 \%$ whereas the external precision of each standard $\delta \mathrm{D}_{\mathrm{IMF}}$ ranged from 1 to $4 \%$ (Table 3 ). Figure $1 \mathrm{a}$ shows SIMS hydrogen isotopic analyses of different spots of the SB-1 turquoise standard made over several analysis sessions. The individual spots IMF values varied between $-585 \%$ and $-575 \%$. The internal precision of ${ }^{65} \mathrm{Cu} /{ }^{63} \mathrm{Cu}$ measurements ranged from 0.3 to $0.4 \%$ whereas the external precision of each standard $\delta \mathrm{Cu}_{\mathrm{IMF}}$ varied between 0.1 and $0.4 \%$ (Table 4). Figure 1a shows SIMS copper isotopic 
analyses of different spots of the SB-1 turquoise standard made over several analysis sessions. The individual spots IMF values varied between $-21.3 \%$ and $-18.6 \%$.

These results show that the spot-to-spot reproducibility was good within each session, which demonstrates that all the turquoise samples selected are sufficiently homogeneous to be suitable calibration standards. The session-to-session variation may be due to changes in instrumental parameters (e.g., mass spectrometer tuning, gun alignment, electron multiplier efficiency). However, no significant variations in IMF were observed when changing sample holder within an individual session. Session-to-session changes in IMF require the instrument to be calibrated every analytical session.

The isotopes ratios measured by SIMS are not correlated with the isotopes ratios determined by conventional techniques (Fig. 2 and 3). This suggests that IMF in turquoise is due to matrix effects for both hydrogen and copper isotopes. As it was previously shown for the SB-1 standard, the isotopes ratios of each standard measured by SIMS are slightly different between analytical sessions. To investigate the relative variation of ratios between standards, the IMF was corrected using the SB-1 standard in each session. The $\mathrm{Cu}$ isotopic values obtained for the other standards after IMF correction show that the relative ratios between standards remain relatively consistent (Fig. 4 and 5). Therefore, few standards can be used for IMF calibration of unknown samples if the relationship between IMF and chemical composition is well established.

\subsection{Matrix effects}

As the instrumental parameters affecting the IMF can be held constant or relatively 
easily corrected, the more problematic contributor to IMF is the matrix effects, which mainly control isotopic fractionation during the ionization stage. Isotopic fractionation during ionization depends on many factors, including binding energy of the surface atoms (bond strength), the mass ratio of the isotopes, the work function of the surface, emission angle, ionization potential, and kinetic energy of both the sputtering and sputtered ions (Riciputi et al., 1998, and references therein). Although various sputtering/ionization models have been proposed for simple chemical compounds, these models generally cannot be applied to more complex geological materials (Riciputi et al., 1998, and references therein). However, empirical models of IMF in minerals or glasses have been established for various light stable isotopes, including hydrogen (Deloule et al., 1991; Hauri et al., 2002; Hauri et al., 2006) or oxygen (Eiler et al., 1997; Hartley et al., 2012; Hervig et al., 1992; Page et al., 2010; Riciputi et al., 1998; Vielzeuf et al., 2005) . To our knowledge, copper isotopes IMF due to matrix effects in geological materials have yet to be reported in the literature .

\subsubsection{Hydrogen}

The hydrogen isotopes IMF is negatively correlated with the $\mathrm{H}$ content and positively correlated with the Fe content (Fig. 6). Such a correlation has been previously observed for silicate glasses (Hauri et al., 2002; Hauri et al., 2006). More precisely, IMF is related to the $\mathrm{H}$ and $\mathrm{Fe}$ contents (in at. \%) by the following exponential model:

$$
\delta \mathrm{D}_{\mathrm{IMF}}=a \exp \left(b \mathrm{Fe}^{0.04} / \mathrm{H}\right)+c
$$

The hydrogen isotopes IMF data obtained during three sessions were fitted using a 
least squares method and an exponential growth model (see Equation [4]). Fitting results are given in the Table 5. Best fits have coefficient of determination $\left(\mathrm{R}^{2}\right)$ values greater than 0.88 , which assessed the quality of the fits. The coefficients values of equation [4] change between the three different analytical sessions, which accounts for the session-to-session instrumental changes. Therefore, at least 3 standards that bracket the $\mathrm{Fe} / \mathrm{H}$ ratio of the unknown samples should be analyzed, in order to delineate the overall shape of the curve and accurately determine the fit coefficients. Standards should be analyzed during the same analysis session as samples to be corrected.

The correction scheme reproduced the actual $\delta \mathrm{D}$ composition of the turquoise standards used to $\pm 5 \%$ for all analytical sessions, except for the CS- 1 sample in the last session (Table 6).

\subsubsection{Copper}

The copper isotopes IMF is positively correlated with the Fe content (Fig. 7). As the Fe content is negatively correlated with the Al content within the turquoisechalcosiderite series (Abdu et al., 2011), the copper isotopes IMF is negatively correlated to the $\mathrm{Al}$ content of turquoise samples. We tested least-square fitting procedures to relate $\mathrm{IMF}$ and $\mathrm{Fe}, \mathrm{Al}, \mathrm{Fe} / \mathrm{Al}$, or $\mathrm{Fe} /(\mathrm{Al}+\mathrm{Fe})$ and best coefficient of determination $\left(\mathrm{R}^{2}\right)$ values (i.e., best fits) were obtained using only the Fe content (in at. \%) with the following model:

$\delta^{65} \mathrm{Cu}_{\mathrm{IMF}}=a \log (\mathrm{Fe})+b$ [5] (see Fig. 7) 
Fitting results for the copper isotopes IMF data obtained during three sessions are given in Table 7. Best fits have coefficient of determination $\left(\mathrm{R}^{2}\right)$ values superior to 0.98, which assessed the quality of the fits. The $a$ coefficients values of equation [5] are similar for the three different analytical sessions whereas the $b$ values accounts for the session-to-session instrumental changes. Therefore at least 2 standards that bracket the chemical composition of the unknown samples (i.e., one Al-rich and one Fe-rich turquoise standard) should be analyzed during each analytical session to correct for the IMF.

Using the appropriate correction schemes for each analytical session, the $\delta^{65} \mathrm{Cu}$ measured by SIMS were reproduced within $\pm 0.5 \%$ of their actual value for all sessions (Table 8).

\section{Applications}

The development of the SIMS calibration method for $\mathrm{H}$ and $\mathrm{Cu}$ isotopic measurements in turquoise may have many applications. Accurate determination of $\mathrm{H}$ and $\mathrm{Cu}$ isotopic composition by the relatively non-destructive SIMS technique may be used to certify the provenance of turquoise, and other $\mathrm{Cu}$-bearing gem minerals, if similar IMF calibration studies are carried out. For example, such analysis could help to identify the source of gem-quality $\mathrm{Cu}$-rich tourmalines. Cu-bearing tourmaline from Paraiba (Brazil) is a highly prized gem mineral and "Paraiba-type" tourmalines of similar colour and quality are produced today from localities in Mozambique and Nigeria. Developing provenance tools for $\mathrm{Cu}$-rich tourmalines is necessary, as their economic value partly depends on their origin. $\mathrm{Li}$ and $\mathrm{B}$ isotopes in $\mathrm{Cu}$-rich tourmalines have been shown to be a suitable provenance tool (Ludwig et al., 2011; 
Shabaga et al., 2010). Although the range in $\mathrm{Cu}$ isotopic composition of tourmalines from pegmatites is unknown, the range in $\mathrm{H}$ isotopic composition can be from $-120 \%$ to $-40 \%$ (Jiang, 1998; Holcombe and Valasquez, 1997), Therefore, the analysis of H and $\mathrm{Cu}$ isotopic composition of $\mathrm{Cu}$-rich tourmalines could provide complementary information.

Apart for provenance determination, $\mathrm{H}$ and $\mathrm{Cu}$ isotopic measurements may also be applied to identify "fake" gems that have been modified from non-gem starting material. For example, such analysis could help to distinguish natural red $\mathrm{Cu}$ bearing plagioclase feldspars from $\mathrm{Cu}$-diffusion treated counterparts. Although red $\mathrm{Cu}$-containing andesine had been thought unique to the state of Oregon, new localities for $\mathrm{Cu}$-bearing feldspars were reported from the Democratic Republic of the Congo, Mongolia and Tibet in the last decade (Rossman, 2011). As the high value of the North America red feldspar partly depends on its strict origin, the new supposedly red feldspars have been the subject of concerns about their provenance and natural color. In fact, many studies suggest that a large part of red feldspars on the market is the product of copper diffusion into pale yellow andesine from Inner Mongolia by laboratory heat treatment (Rossman, 2011). Measuring $\mathrm{Cu}$ isotope ratios in $\mathrm{Cu}$ bearing andesine has proven to be helpful in determining their authenticity and provenance, as laboratory diffused samples show a greater intra-sample variability for ${ }^{65} \mathrm{Cu} /{ }^{63} \mathrm{Cu}$ due to the diffusion process (Fontaine et al., 2010). In addition, comparing the $\mathrm{Cu}$ isotope ratios of two minerals without depth-profiling does not allow distinguishing between a naturally colored and a $\mathrm{Cu}$-diffused andesine, as the copper isotopic composition of treated samples may be influenced by many factors (e.g., isotope composition of the treatment, exposure time, temperature). 
The analysis of $\mathrm{H}$ and $\mathrm{Cu}$ isotopic ratios by SIMS may also be useful for identifying the provenance of archaeological artifacts. For example, source regions of turquoise artifacts from the American Southwest have been identified by measuring the isotopic ratios of hydrogen and copper (Hull and Fayek, 2012; Hull et al., 2008). The measurement of $\mathrm{D} /{ }^{1} \mathrm{H}$ and ${ }^{65} \mathrm{Cu} /{ }^{63} \mathrm{Cu}$ was indeed successful in identifying unique fingerprints for different turquoise mines, thus allowing determination of the provenance of turquoise artifacts and improving the understanding of pre-Columban turquoise trade networks.

\section{Conclusions}

SIMS analyses of $\mathrm{D} / \mathrm{H}$ and ${ }^{65} \mathrm{Cu} /{ }^{63} \mathrm{Cu}$ ratios in turquoise reveal that variations in IMF are correlated with the abundance of water and iron of the samples. The strong matrix effect observed $(\sim 20 \%$ of $\mathrm{H}$ and $\sim 7 \%$ for $\mathrm{Cu}$ ) illustrates the importance of evaluating such effects in isotope analysis by SIMS because the overall natural ranges in $\mathrm{H}$ and $\mathrm{Cu}$ isotopic composition for turquoise are $\sim 80 \%$ and $16 \%$, respectively (Hull et al., 2014). Correction models have been proposed to calibrate IMF for matrix effects: (1) an exponential growth model based on the $\mathrm{H}$ and Fe contents for $\mathrm{D} / \mathrm{H}$ measurements, (2) a logarithmic model based on the Fe content for the ${ }^{65} \mathrm{Cu} /{ }^{63} \mathrm{Cu}$ measurements. All the standards used in this study have been shown to be suitable for use as calibration standards in $\delta \mathrm{D}$ and $\delta^{65} \mathrm{Cu}$ analysis in turquoise by SIMS. Although the absolute value of the IMF changes with instrumental conditions (e.g., tuning or electron multiplier efficiency) between two sessions, the relationship between IMF and chemical composition remains similar. Therefore at least two (for ${ }^{65} \mathrm{Cu} /{ }^{63} \mathrm{Cu}$ analysis) or three (for D/H analysis) standards that compositionally bracket the 
unknown should be analyzed during every analytical session to obtain a reliable correction scheme.

This study demonstrates that accurate and reliable hydrogen and copper isotopes ratios may be measured in turquoise by SIMS, once the hydrogen and iron contents of unknown samples are known. The use of SIMS to analyse (semi-) precious gem minerals or archeological artifacts has some advantages over bulk isotope analyses methods as it is a relatively non-destructive technique and allows to analyse samples, which contain mineralogical heterogeneities or are partly altered.

\section{Acknowledgements}

This research has been supported by the Canadian Foundation for Innovation (Fayek), Natural Sciences and Engineering Council of Canada Discovery Grant (Fayek) and Europole Mer (Rouxel). The authors would like to thank Brandi Shabaga (University of Manitoba) and Emmanuel Ponzevera (IFREMER) for help in laboratory.

\section{Figures captions}

Figure 1. Plots of (a) hydrogen and (b) copper isotopic values showing the spot to spot reproducibility during SIMS analytical sessions for the SB-1 sample.

Figure 2. D/H as a function of the "true" D/H values determined by GS-MS. Vertical error bars correspond to the SIMS external precision of the measurements. The symbol width is larger than the horizontal GS-MS error bars in all cases.

Figure 3. ${ }^{65} \mathrm{Cu} /{ }^{63} \mathrm{Cu}$ as a function of the "true" ${ }^{65} \mathrm{Cu} /{ }^{63} \mathrm{Cu}$ values determined by MCICP-MS. Vertical error bars correspond to the SIMS external precision of the 
measurements. The symbol width is larger than the horizontal MC-ICP-MS error bars in all cases.

Figure 4. $\delta D_{\text {SIMS }}$ of four turquoise standards for three sessions. IMF was corrected using the SB-1 standard and $\delta \mathrm{D}$ values are reported relative to the V-SMOW standard. Vertical error bars correspond to the SIMS external precision of the measurements.

Figure 5. $\delta^{65} \mathrm{Cu}_{\text {SIMS }}$ of four turquoise standards for three sessions. IMF was corrected using the SB-1 standard and $\delta^{65} \mathrm{Cu}$ values are reported relative to the NIST 976 standard. Vertical error bars correspond to the SIMS external precision of the measurements.

Figure 6. $\delta \mathrm{D}_{\mathrm{IMF}}$ as a function of $\mathrm{Fe}^{0.04} / \mathrm{H}(\mathrm{Fe}$ and $\mathrm{H}$ in at. \%) in the turquoise standards for three sessions. Horizontal error bars correspond to the $\mathrm{Fe}^{0.04} / \mathrm{H}$ error based on the standard deviation of $\mathrm{H}$ and $\mathrm{Fe}$ at. \% analyses by EPMA. Vertical error bars correspond to the SIMS external precision of the measurements.

Figure 7. $\delta^{65} \mathrm{Cu}_{\mathrm{IMF}}$ as a function of $\log (\mathrm{Fe})(\mathrm{Fe}$ in at. \%) in the turquoise standards for three sessions. Horizontal error bars correspond to the $\log (\mathrm{Fe})$ error based on the standard deviation of Fe at. \% analyses by EPMA. Vertical error bars correspond to the external precision of the measurements.

\section{References}

Abdu, Y.A., Hull, S.K., Fayek, M., Hawthorne, F.C., 2011. The turquoisechalcosiderite $\mathrm{Cu}(\mathrm{Al}, \mathrm{Fe} 3+) 6(\mathrm{PO}) 4(\mathrm{OH}) 8.4 \mathrm{H} 20$ solid-solution series: A Mössbauer spectroscopy, XRD, EMPA, and FTIR study. American Mineralogist, 96(10): 1433-1442.

Bell, D.R., Hervig, R.L., Buseck, P.R., Aulbach, S., 2009. Lithium isotope analysis of olivine by SIMS: Calibration of a matrix effect and application to magmatic phenocrysts. Chemical Geology, 258(1): 5-16. 
Bigeleisen, J., Perlman, M., Prosser, H., 1952. Conversion of hydrogenic materials to hydrogen for isotopic analysis. Analytical Chemistry, 24(8): 1356-1357.

Borrok, D., Wanty, R., Ridley, W., Wolf, R., Lamothe, P., Adams, M., 2007. Separation of copper, iron, and zinc from complex aqueous solutions for isotopic measurement. Chemical Geology, 242(3): 400-414.

Chapman, J.B., Mason, T.F., Weiss, D.J., Coles, B.J., Wilkinson, J.J., 2006. Chemical separation and isotopic variations of $\mathrm{Cu}$ and $\mathrm{Zn}$ from five geological reference materials. Geostandards and Geoanalytical Research, 30(1): 516.

Darque-Ceretti, E., Aucouturier, M., 2004. Secondary ion mass spectrometry. Application to archaeology and art objects. Non-destructive Analysis of Cultural Heritage Materials: 397-461.

Deloule, E., France-Lanord, C., Albarède, F., 1991. D/H analysis of minerals by ion probe. Stable Isotope Geochemistry: A Tribute to Samuel Epstein Geochemical Society, Special Publication, 3: 53-62.

Dowsett, M., Adriaens, A., 2004. The role of SIMS in cultural heritage studies. Nuclear Instruments and Methods in Physics Research Section B: Beam Interactions with Materials and Atoms, 226(1): 38-52.

Eiler, J.M., Graham, C., Valley, J.W., 1997. SIMS analysis of oxygen isotopes: matrix effects in complex minerals and glasses. Chemical Geology, 138(3-4): 221244.

Fayek, M. (Ed.), 2009. Secondary Ion Mass Spectrometry in the Earth Siences, Mineralogical Association of Canada Short Course Volume 41.

Fontaine, G.H., Hametner, K., Peretti, A., Günther, D., 2010. Authenticity and provenance studies of copper-bearing andesines using $\mathrm{Cu}$ isotope ratios and element analysis by fs-LA-MC-ICPMS and ns-LA-ICPMS. Analytical and bioanalytical chemistry, 398(7-8): 2915-2928.

Foord, E.E., Taggart, J.E., 1998. A reexamination of the turquoise group: the mineral aheylite, planerite (redefined), turquoise and coeruleolactite. Mineralogical Magazine, 62(1): 93-111.

Giuliani, G., Chaussidon, M., Schubnel, H.-J., Piat, D.H., Rollion-Bard, C., FranceLanord, C., Giard, D., de Narvaez, D., Rondeau, B., 2000. Oxygen isotopes and emerald trade routes since antiquity. Science, 287(5453): 631-633.

Graham, S., Pearson, N., Jackson, S., Griffin, W., O'Reilly, S., 2004. Tracing Cu and Fe from source to porphyry: in situ determination of $\mathrm{Cu}$ and $\mathrm{Fe}$ isotope ratios in sulfides from the Grasberg $\mathrm{Cu}-\mathrm{Au}$ deposit. Chemical Geology, 207(3): 147-169.

Hagemann, R., Nief, G., Roth, E., 1970. Absolute isotopic scale for deuterium analysis of natural waters. Absolute D/H ratio for SMOW1. Tellus, 22(6): 712-715.

Hartley, M., Thordarson, T., Taylor, C., Fitton, J., 2012. Evaluation of the effects of composition on instrumental mass fractionation during SIMS oxygen isotope analyses of glasses. Chemical Geology.

Hauri, E., Wang, J., Dixon, J.E., King, P.L., Mandeville, C., Newman, S., 2002. SIMS analysis of volatiles in silicate glasses: 1 . Calibration, matrix effects and comparisons with FTIR. Chemical Geology, 183(1): 99-114.

Hauri, E.H., Shaw, A.M., Wang, J., Dixon, J.E., King, P.L., Mandeville, C., 2006. Matrix effects in hydrogen isotope analysis of silicate glasses by SIMS. Chemical Geology, 235(3): 352-365. 
Hervig, R.L., Williams, P., Thomas, R.M., Schauer, S.N., Steele, I.M., 1992. Microanalysis of oxygen isotopes in insulators by secondary ion mass spectrometry. International Journal of Mass Spectrometry and Ion Processes, 120(1-2): 45-63.

Holcombe, B., Valasquez, M., 1997. Stable isotope variations in pegmatite systems associated with the Sebago batholith, southwestern Maine. Abstract, 10 th Keck Symposium, College of Wooster, April 1, 1997: 191194

Hull, S., Fayek, M., Mathien, F.J., Roberts, H., 2014. Turquoise trade of the ancestral puebloan: Chaco and beyond. Journal of Archaeological Science, 45 (1): 187-195.

Hull, S., Fayek, M., 2012. Cracking the Code of Pre-Columbian Turquoise Trade Networks and Procurement Strategies. In: King, J.C.H., Carocci, M., Cartwright, C., Mc Ewan, C., Stacey, R. (Eds.), Turquoise in Mexico and North America: Science, Conservation, Culture and Collections. Archetype Publications in Association with the British Museum, London, pp. 29-40.

Hull, S., Fayek, M., Mathien, F.J., Shelley, P., Durand, K.R., 2008. A new approach to determining the geological provenance of turquoise artifacts using hydrogen and copper stable isotopes. Journal of Archaeological Science, 35(5): 1355-1369.

Ikehata, K., Notsu, K., Hirata, T., 2008. In situ determination of $\mathrm{Cu}$ isotope ratios in copper-rich materials by NIR femtosecond LA-MC-ICP-MS. Journal of Analytical Atomic Spectrometry, 23(7): 1003-1008.

Ireland, T.R., 2013. Invited Review Article: Recent developments in isotope-ratio mass spectrometry for geochemistry and cosmochemistry. Review of Scientific Instruments, 84(1): 1-21.

Jiang, S-Y., 1998. Stable and radiogenic studies of tourmaline: An overview. Journal of the Czech Geological Society, 43 (1-2): 75-90.

Kyser, T.K., O'Neil, J.R., 1984. Hydrogen isotope systematics of submarine basalts. Geochimica et Cosmochimica Acta, 48(10): 2123-2133.

Li, W., Jackson, S.E., Pearson, N.J., Graham, S., 2010. Copper isotopic zonation in the Northparkes porphyry $\mathrm{Cu}-\mathrm{Au}$ deposit, SE Australia. Geochimica et Cosmochimica Acta, 74(14): 4078-4096.

Liu, R., Hull, S., Fayek, M., 2011. A new approach to measuring D/H ratios with the Cameca IMS-7F. Surface and Interface Analysis, 43(1-2): 458-461.

Ludwig, T., Marschall, H., von Strandmann, P.P., Shabaga, B., Fayek, M., Hawthorne, F., 2011. A secondary ion mass spectrometry (SIMS) reevaluation of $\mathrm{B}$ and $\mathrm{Li}$ isotopic compositions of $\mathrm{Cu}$-bearing elbaite from three global localities. Mineralogical Magazine, 75(4): 2485-2494.

MacRae, N.D., 1995. Secondary-ion mass spectrometry and geology. The Canadian Mineralogist, 33(2): 219-236.

Maréchal, C.N., Albarède, F., 2002. Ion-exchange fractionation of copper and zinc isotopes. Geochimica et Cosmochimica Acta, 66(9): 1499-1509.

Maréchal, C.N., Télouk, P., Albarède, F., 1999. Precise analysis of copper and zinc isotopic compositions by plasma-source mass spectrometry. Chemical Geology, 156(1): 251-273.

Page, F.Z., Kita, N.T., Valley, J.W., 2010. Ion microprobe analysis of oxygen isotopes in garnets of complex chemistry. Chemical Geology, 270: 9-19. 
Palacios, C., Rouxel, O., Reich, M., Cameron, E.M., Leybourne, M.I., 2011.

Pleistocene recycling of copper at a porphyry system, Atacama Desert,

Chile: $\mathrm{Cu}$ isotope evidence. Mineralium Deposita, 46(1): 1-7.

Reed, S., 1989. Ion microprobe analysis, a review of geological applications. Mineralogical Magazine, 53(369): 3-24.

Riciputi, L.R., Paterson, B.A., Ripperdan, R.L., 1998. Measurement of light stable isotope ratios by SIMS: Matrix effects for oxygen, carbon, and sulfur isotopes in minerals. International Journal of Mass Spectrometry, 178(1): 81-112.

Rossman, G.R., 2011. The Chinese red feldspar controversy: Chronology of research through July 2009. Gems \& Gemology, 47(1): 16-30.

Rouxel, O., Fouquet, Y., Ludden, J.N., 2004. Copper isotope systematics of the Lucky Strike, Rainbow, and Logatchev sea-floor hydrothermal fields on the Mid-Atlantic Ridge. Economic Geology, 99(3): 585-600.

Shabaga, B., Fayek, M., Hawthorne, F., 2010. Boron and lithium isotopic compositions as provenance indicators of $\mathrm{Cu}$-bearing tourmalines. Mineralogical Magazine, 74(2): 241-255.

Sharp, Z., Atudorei, V., Durakiewicz, T., 2001. A rapid method for determination of hydrogen and oxygen isotope ratios from water and hydrous minerals. Chemical Geology, 178(1): 197-210.

Shields, W.R., Murphy, T.J., Garner, E.L., 1964. Absolute isotopic abundance ratio and the atomic weight of a reference sample of copper. Journal of research of the national bureau of standards, 68A: 589-92.

Valley, J.W., Kita, N.T., 2009. In situ oxygen isotope geochemistry by ion microprobe. MAC short course: secondary ion mass spectrometry in the earth sciences, 41: 19-63.

Vielzeuf, D., Champenois, M., Valley, J.W., Brunet, F., Devidal, J., 2005. SIMS analyses of oxygen isotopes: matrix effects in Fe-Mg-Ca garnets. Chemical Geology, 223(4): 208-226.

Walker, E.C., Cuttitta, F., Senftle, F.E., 1958. Some natural variations in the relative abundance of copper isotopes. Geochimica et Cosmochimica Acta, 15(3): 183-194. 
Figure 1

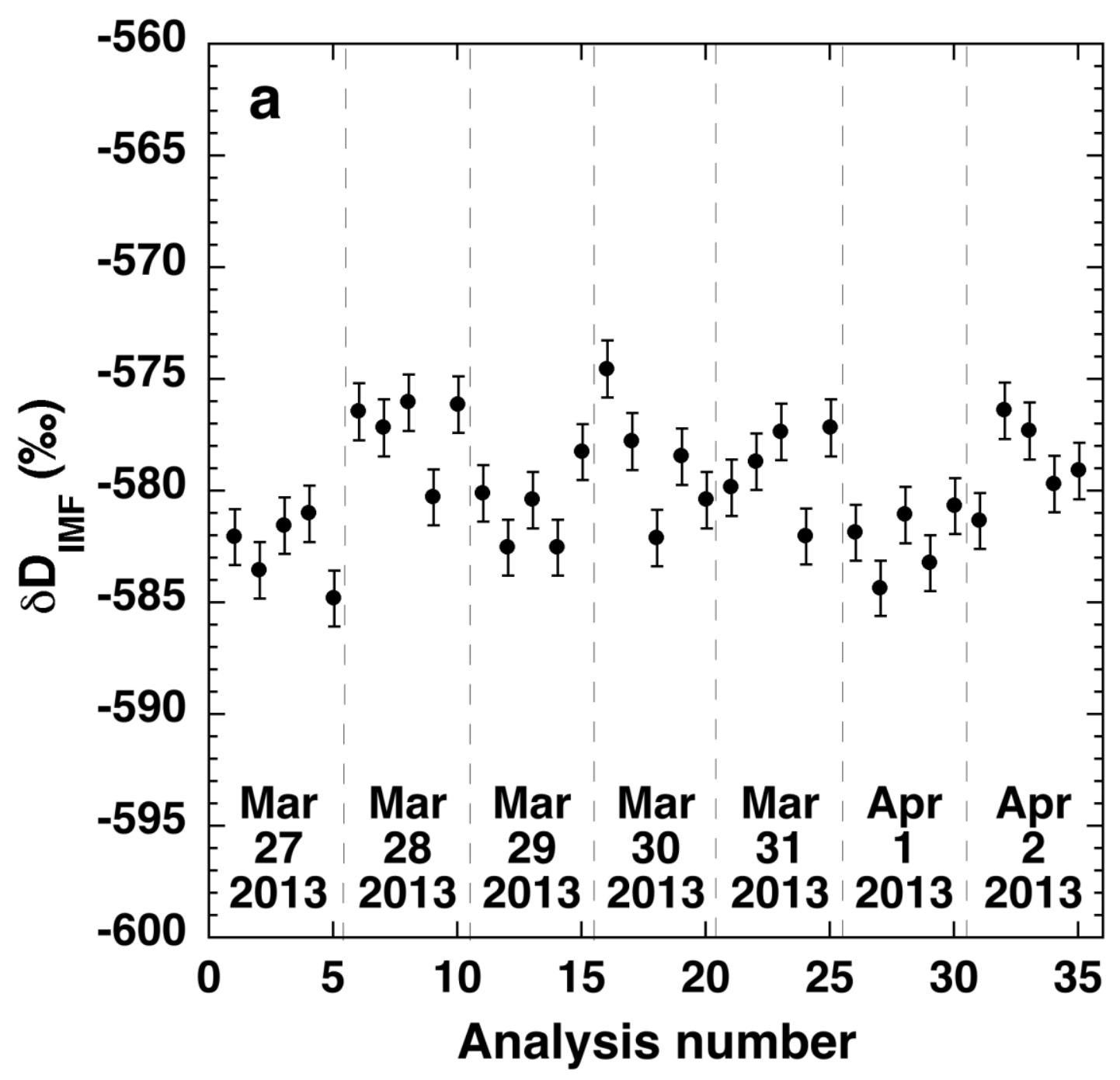




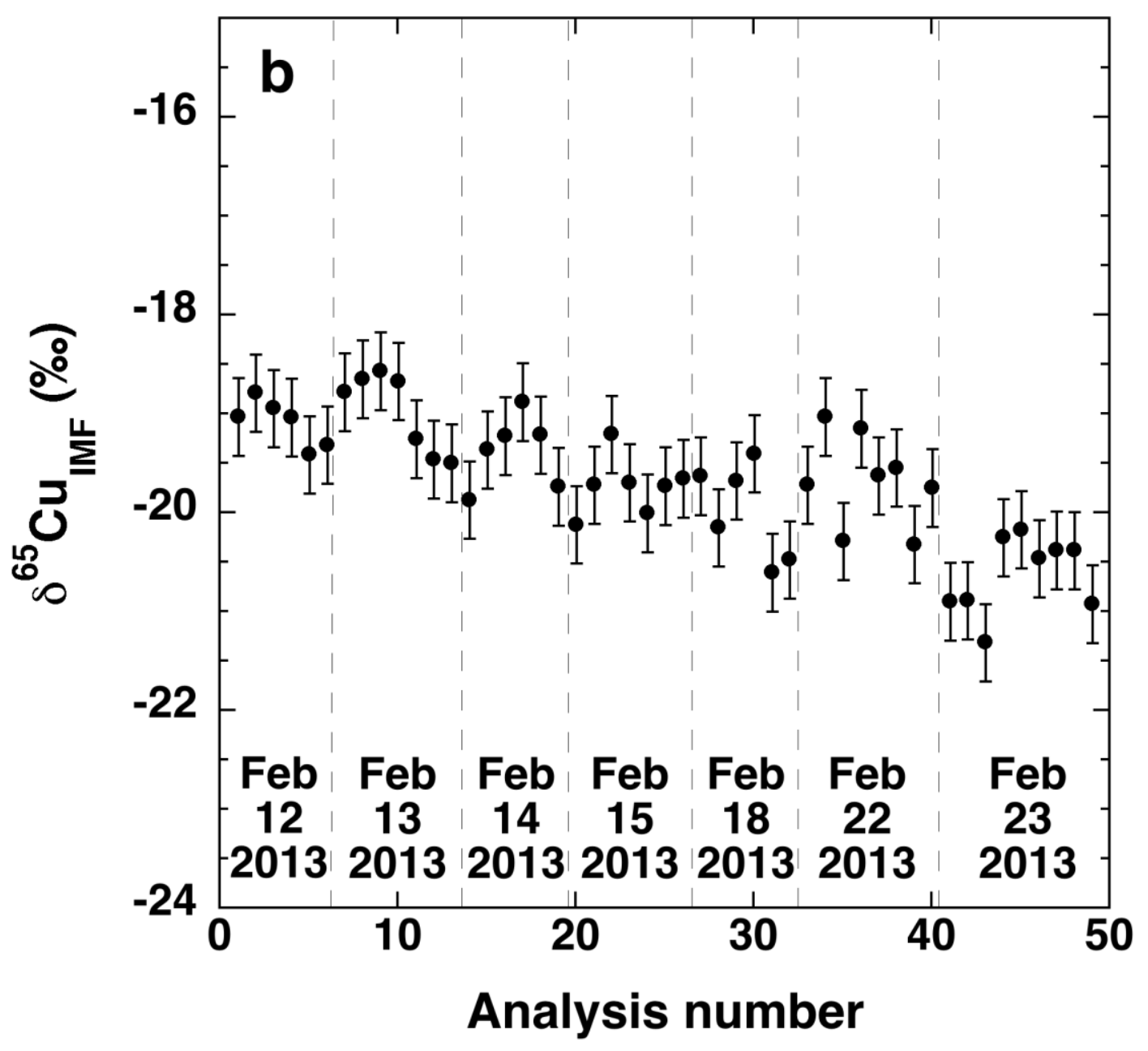

Figure 1 
Figure 2

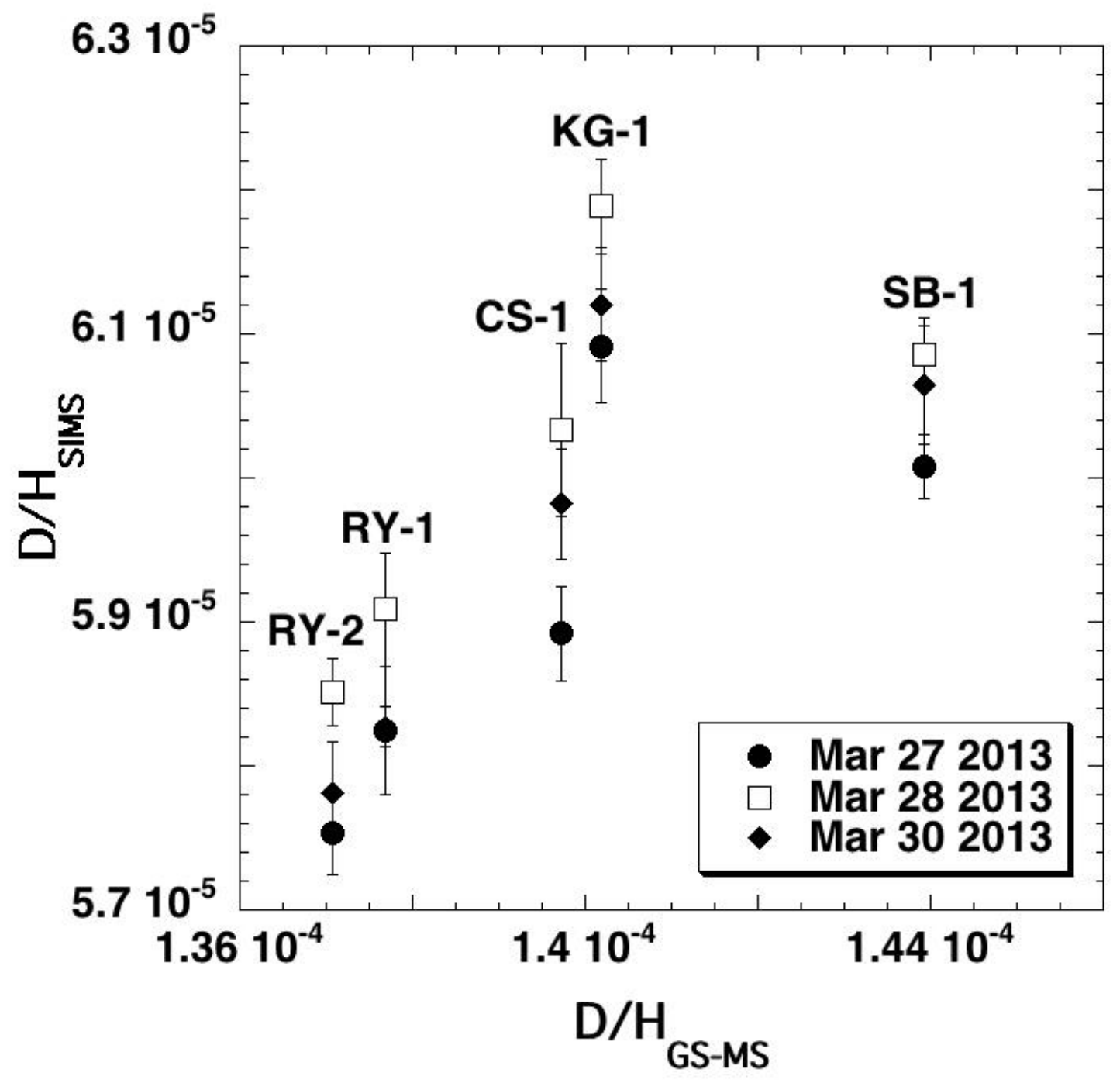


Figure 3

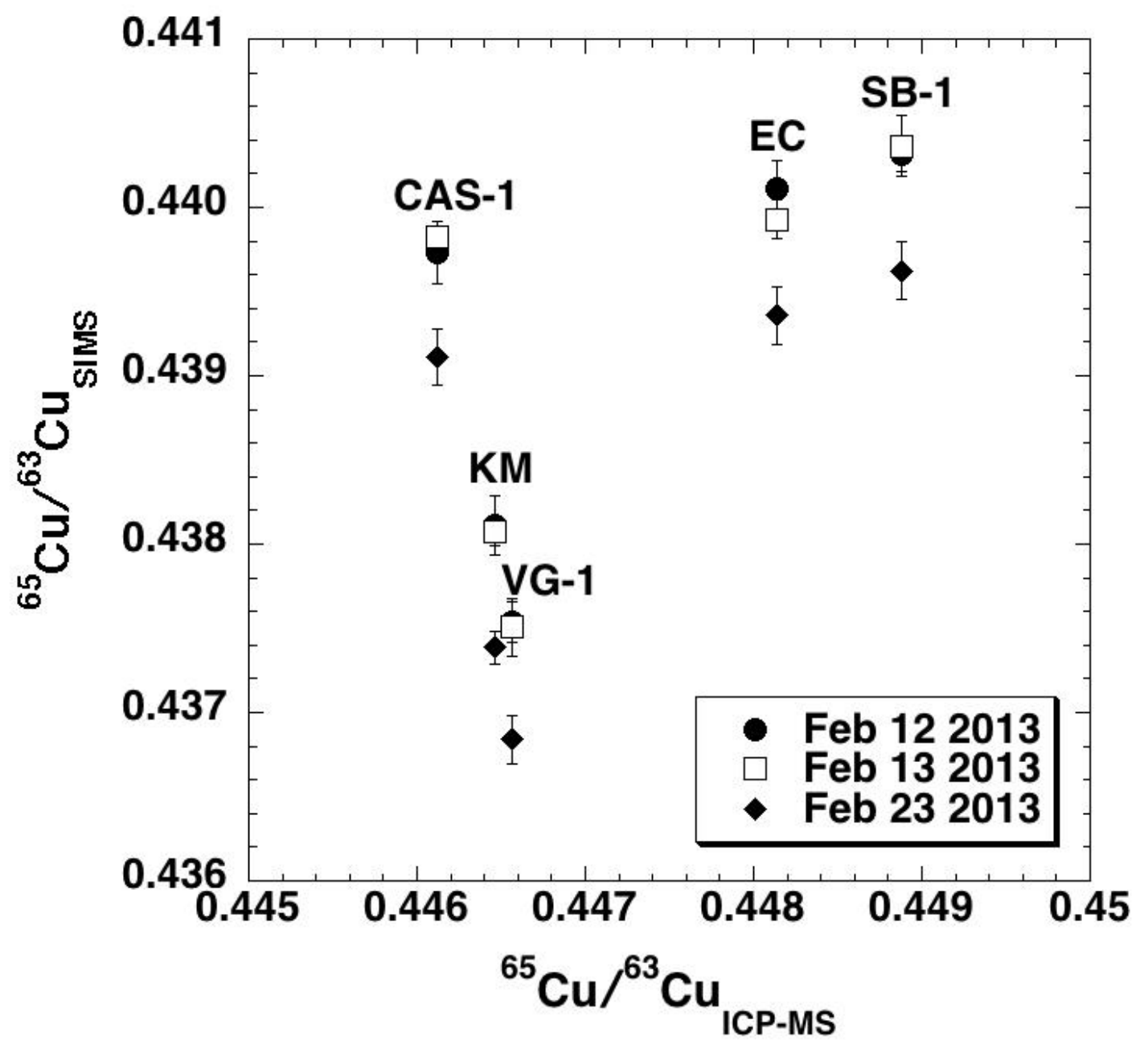


Figure 4

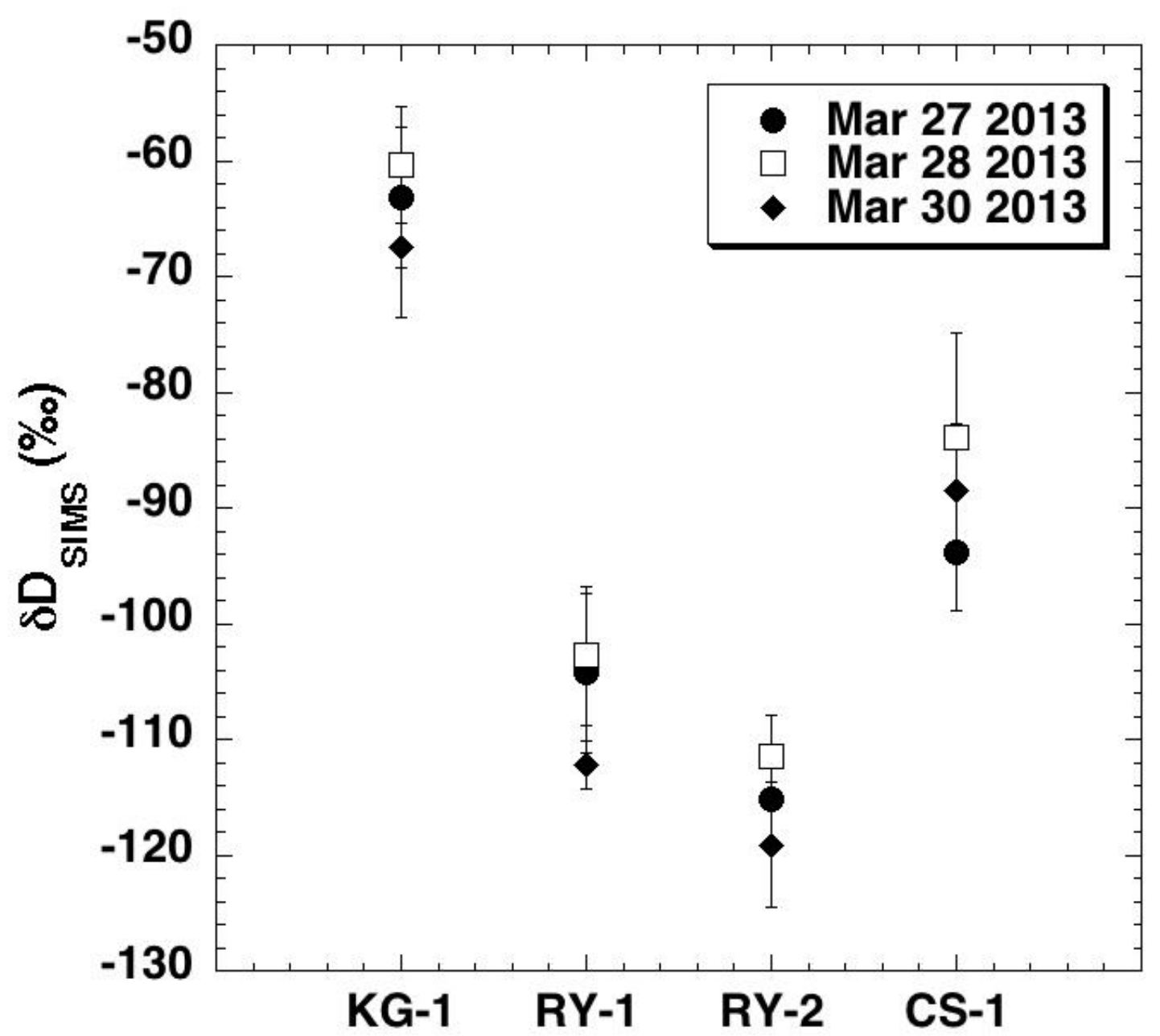


Figure 5

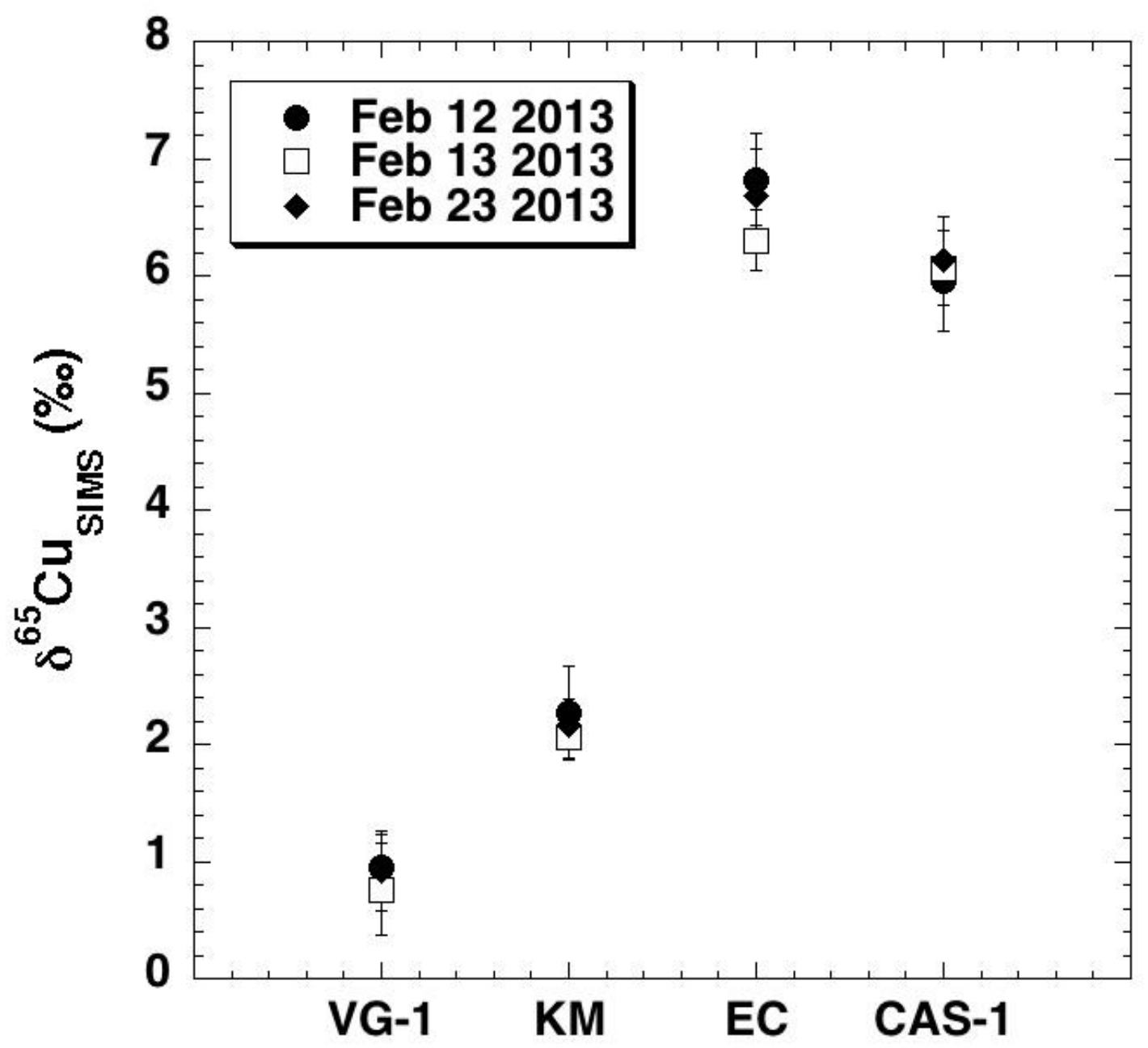



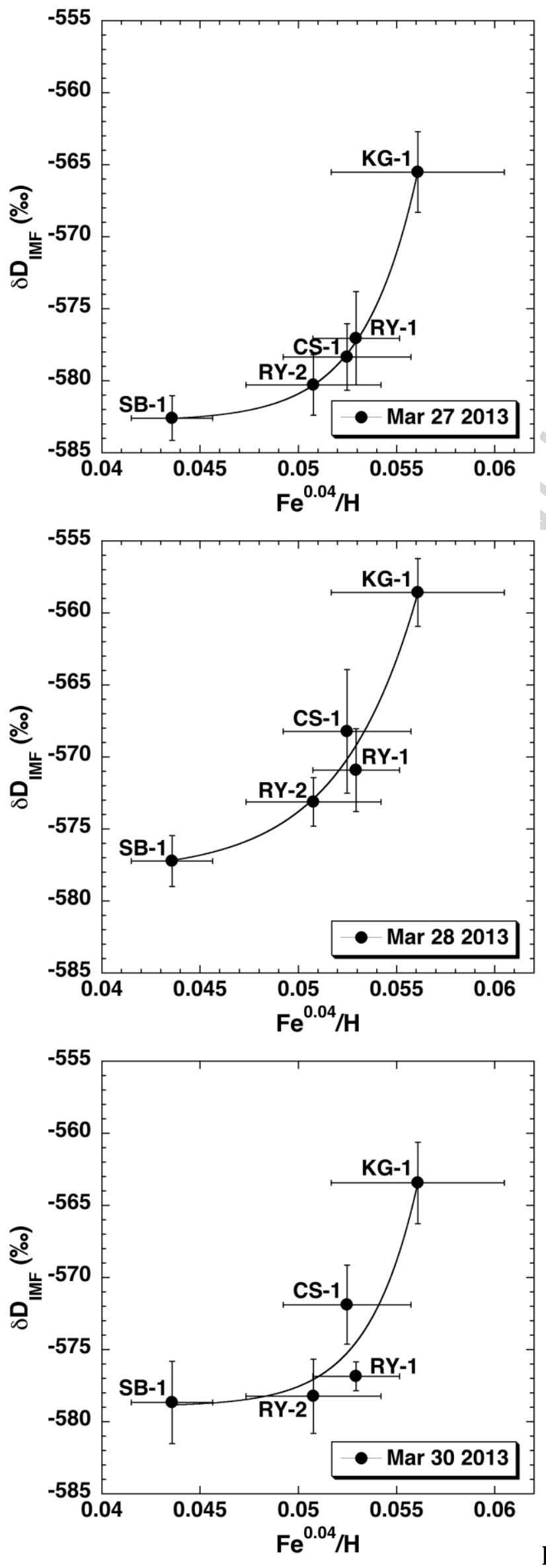

Figure 6 

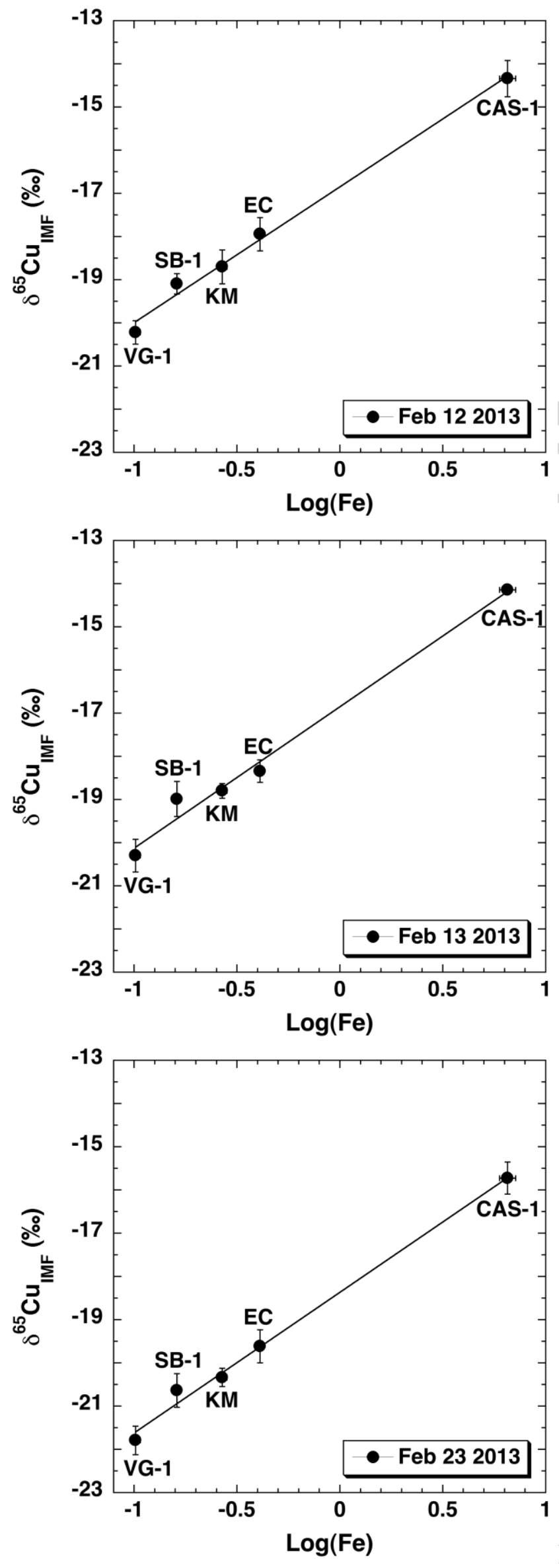

Figure 7 
Table 1. Turquoise samples provenance.

\begin{tabular}{cc}
\hline Sample(s) & Provenance \\
\hline VG-1 & Villa Grove, San Luis Valley, Colorado, U.S.A. \\
SB-1 & Sleeping Beauty, Globe District, Arizona, U.S.A. \\
FX & Fox Mine, Cortez, Nevada, U.S.A. \\
EC & East Camp, Halloran Springs, California, U.S.A. \\
GT-1 & Green Tree, Cortez, Nevada, U.S.A. \\
KG-1 & Kingman, Mineral Park, Arizona, U.S.A. \\
RY-1, RY-2 & Royston, Nevada, U.S.A. \\
CS-1, CAS-1 & Castillian Mine, Cerrillos Hills, New Mexico, U.S.A.
\end{tabular}


Table 2. Major element and isotopic compositions of the turquoise standards used in this study. Standard deviations of the 5-10 EPMA analytical spots per standard are given in parentheses.

\begin{tabular}{|c|c|c|c|c|c|c|c|c|c|c|}
\hline & VG-1 & SB-1 & FX & $\mathrm{EC}$ & GT-1 & KG-1 & RY-1 & RY-2 & CS-1 & CAS-1 \\
\hline \multicolumn{11}{|c|}{ Major (wt. \%) } \\
\hline $\mathrm{Na}_{2} \mathrm{O}$ & n.d. ${ }^{a}$ & n.d. & $\begin{array}{c}0.02 \\
(0.01)\end{array}$ & $\begin{array}{c}0.01 \\
(0.01)\end{array}$ & $\begin{array}{c}0.02 \\
(0.02)\end{array}$ & n.d. & n.d. & & n.d. & n.d. \\
\hline $\mathrm{MgO}$ & n.d. & $\begin{array}{c}0.01 \\
(0.01)\end{array}$ & n.d. & $\begin{array}{c}0.01 \\
(0.01)\end{array}$ & $\begin{array}{c}0.01 \\
(0.01)\end{array}$ & $\begin{array}{c}0.01 \\
(0.01)\end{array}$ & $\begin{array}{c}0.01 \\
(0.01)\end{array}$ & $\begin{array}{l}0.01 \\
(0.01)\end{array}$ & $\begin{array}{c}0.01 \\
(0.01)\end{array}$ & n.d. \\
\hline $\mathrm{Al}_{2} \mathrm{O}_{3}$ & $\begin{array}{l}42.34 \\
(0.37)\end{array}$ & $\begin{array}{l}41.69 \\
(0.70)\end{array}$ & $\begin{array}{l}41.03 \\
(0.39)\end{array}$ & $\begin{array}{l}40.47 \\
(0.44)\end{array}$ & $\begin{array}{l}40.83 \\
(0.24)\end{array}$ & $\begin{array}{l}42.27 \\
(0.12)\end{array}$ & $\begin{array}{l}40.73 \\
(0.28)\end{array}$ & $\begin{array}{r}40.28 \\
(0.84)\end{array}$ & $\begin{array}{l}31.10 \\
(0.69)\end{array}$ & $\begin{array}{l}20.54 \\
(1.32)\end{array}$ \\
\hline $\mathrm{SiO}_{2}$ & $\begin{array}{c}0.01 \\
(0.01)\end{array}$ & $\begin{array}{c}0.02 \\
(0.01)\end{array}$ & $\begin{array}{l}1.00 \\
(0.05)\end{array}$ & $\begin{array}{c}0.96 \\
(0.05)\end{array}$ & $\begin{array}{c}0.25 \\
(0.03)\end{array}$ & $\begin{array}{c}0.02 \\
(0.02)\end{array}$ & $\begin{array}{c}0.65 \\
(0.03)\end{array}$ & $\begin{array}{c}0.45 \\
(0.03)\end{array}$ & $\begin{array}{c}0.02 \\
(0.01)\end{array}$ & $\begin{array}{c}0.02 \\
(0.01)\end{array}$ \\
\hline $\mathrm{P}_{2} \mathrm{O}_{5}$ & $\begin{array}{l}36.66 \\
(0.38)\end{array}$ & $\begin{array}{l}36.25 \\
(0.34)\end{array}$ & $\begin{array}{l}34.59 \\
(0.48)\end{array}$ & $\begin{array}{l}35.13 \\
(0.12)\end{array}$ & $\begin{array}{c}35.82 \\
(0.16)\end{array}$ & $\begin{array}{l}36.91 \\
(0.46)\end{array}$ & $\begin{array}{l}36.39 \\
(0.15)\end{array}$ & $\begin{array}{l}35.63 \\
(0.17)\end{array}$ & $\begin{array}{l}34.38 \\
(0.39)\end{array}$ & $\begin{array}{l}32.85 \\
(0.31)\end{array}$ \\
\hline $\mathrm{SO}_{2}$ & $\begin{array}{c}0.12 \\
(0.01)\end{array}$ & $\begin{array}{c}0.34 \\
(0.01)\end{array}$ & $\begin{array}{c}0.49 \\
(0.04)\end{array}$ & $\begin{array}{c}0.13 \\
(0.01)\end{array}$ & $\begin{array}{c}0.13 \\
(0.01)\end{array}$ & $\begin{array}{c}0.27 \\
(0.02)\end{array}$ & $\begin{array}{c}0.14 \\
(0.02)\end{array}$ & $\begin{array}{c}0.14 \\
(0.01)\end{array}$ & $\begin{array}{c}0.43 \\
(0.02)\end{array}$ & $\begin{array}{c}0.76 \\
(0.05)\end{array}$ \\
\hline $\mathrm{K}_{2} \mathrm{O}$ & $\begin{array}{c}0.05 \\
(0.01)\end{array}$ & $\begin{array}{c}0.07 \\
(0.01)\end{array}$ & $\begin{array}{c}0.08 \\
(0.01)\end{array}$ & $\begin{array}{c}0.06 \\
(0.01)\end{array}$ & $\begin{array}{c}0.04 \\
(0.01)\end{array}$ & $\begin{array}{c}0.06 \\
(0.01)\end{array}$ & $\begin{array}{c}0.04 \\
(0.01)\end{array}$ & $\begin{array}{c}0.05 \\
(0.01)\end{array}$ & $\begin{array}{c}0.08 \\
(0.01)\end{array}$ & $\begin{array}{c}0.06 \\
(0.01)\end{array}$ \\
\hline $\mathrm{CaO}$ & $\begin{array}{c}0.04 \\
(0.01)\end{array}$ & $\begin{array}{c}0.02 \\
(0.01)\end{array}$ & $\begin{array}{c}0.23 \\
(0.01)\end{array}$ & $\begin{array}{c}0.17 \\
(0.01)\end{array}$ & $\begin{array}{c}0.20 \\
(0.01)\end{array}$ & $\begin{array}{c}0.04 \\
(0.01)\end{array}$ & $\begin{array}{c}0.08 \\
(0.01)\end{array}$ & $\begin{array}{c}0.09 \\
(0.01)\end{array}$ & $\begin{array}{c}0.09 \\
(0.01)\end{array}$ & $\begin{array}{c}0.01 \\
(0.01)\end{array}$ \\
\hline $\mathrm{TiO}_{2}$ & $\begin{array}{c}0.01 \\
(0.01)\end{array}$ & $\begin{array}{c}0.06 \\
(0.02)\end{array}$ & $\begin{array}{c}0.01 \\
(0.01)\end{array}$ & n.d. & $\begin{array}{c}0.01 \\
(0.01)\end{array}$ & $\begin{array}{c}0.02 \\
(0.01)\end{array}$ & $\begin{array}{c}0.01 \\
(0.01)\end{array}$ & $\begin{array}{c}0.01 \\
(0.01)\end{array}$ & $\begin{array}{c}0.01 \\
(0.01)\end{array}$ & $\begin{array}{c}0.05 \\
(0.01)\end{array}$ \\
\hline $\mathrm{Cr}_{2} \mathrm{O}_{3}$ & $\begin{array}{c}0.03 \\
(0.02)\end{array}$ & $\begin{array}{c}0.01 \\
(0.01)\end{array}$ & $\begin{array}{c}0.16 \\
(0.02)\end{array}$ & $\begin{array}{c}0.01 \\
(0.01)\end{array}$ & $\begin{array}{c}0.09 \\
(0.01)\end{array}$ & $\begin{array}{c}0.02 \\
(0.01)\end{array}$ & $\begin{array}{c}0.01 \\
(0.02)\end{array}$ & $\begin{array}{c}0.02 \\
(0.01)\end{array}$ & $\begin{array}{c}0.01 \\
(0.01)\end{array}$ & $\begin{array}{c}0.01 \\
(0.01)\end{array}$ \\
\hline $\mathrm{Fe}_{2} \mathrm{O}_{3}$ & $\begin{array}{c}0.49 \\
(0.03)\end{array}$ & $\begin{array}{c}0.77 \\
(0.03)\end{array}$ & $\begin{array}{l}1.27 \\
(0.06)\end{array}$ & $\begin{array}{c}1.95 \\
(0.07)\end{array}$ & $\begin{array}{c}2.19 \\
(0.27)\end{array}$ & $\begin{array}{c}2.25 \\
(0.13)\end{array}$ & $\begin{array}{c}2.57 \\
(0.14)\end{array}$ & $\begin{array}{c}3.64 \\
(0.21)\end{array}$ & $\begin{array}{l}15.40 \\
(0.77)\end{array}$ & $\begin{array}{l}28.25 \\
(2.09)\end{array}$ \\
\hline $\mathrm{CuO}$ & $\begin{array}{c}8.27 \\
(0.20)\end{array}$ & $\begin{array}{c}9.08 \\
(0.11)\end{array}$ & $\begin{array}{c}8.78 \\
(0.05)\end{array}$ & $\begin{array}{c}9.18 \\
(0.05)\end{array}$ & $\begin{array}{c}7.34 \\
(0.45)\end{array}$ & $\begin{array}{c}8.69 \\
(0.19)\end{array}$ & $\begin{array}{c}9.72 \\
(0.15)\end{array}$ & $\begin{array}{c}9.32 \\
(0.13)\end{array}$ & $\begin{array}{c}8.16 \\
(0.17)\end{array}$ & $\begin{array}{c}7.03 \\
(0.42)\end{array}$ \\
\hline $\mathrm{ZnO}$ & $\begin{array}{c}0.17 \\
(0.02)\end{array}$ & $\begin{array}{c}0.01 \\
(0.02)\end{array}$ & $\begin{array}{c}0.30 \\
(0.03)\end{array}$ & $\begin{array}{c}0.22 \\
(0.05)\end{array}$ & $\begin{array}{c}1.98 \\
(0.44)\end{array}$ & $\begin{array}{c}0.46 \\
(0.05)\end{array}$ & $\begin{array}{c}0.03 \\
(0.02)\end{array}$ & $\begin{array}{c}0.06 \\
(0.04)\end{array}$ & $\begin{array}{c}0.09 \\
(0.03)\end{array}$ & $\begin{array}{c}0.01 \\
(0.02)\end{array}$ \\
\hline $\mathrm{H}_{2} \mathrm{O}^{\mathrm{b}}$ & $\begin{array}{l}11.79 \\
(0.47)\end{array}$ & 11 & $\begin{array}{l}12.00 \\
(0.58)\end{array}$ & $\begin{array}{l}11.65 \\
(0.63)\end{array}$ & $\begin{array}{l}11.05 \\
(0.39)\end{array}$ & $\begin{array}{c}8.92 \\
(0.88)\end{array}$ & $\begin{array}{c}9.58 \\
(0.51)\end{array}$ & $\begin{array}{l}10.25 \\
(0.89)\end{array}$ & $\begin{array}{l}10.17 \\
(0.79)\end{array}$ & $\begin{array}{l}10.39 \\
(0.75)\end{array}$ \\
\hline Isotope & & & & & & & & & & \\
\hline$\delta \mathrm{D}_{\mathrm{VSM}}$ & & & $\mathrm{n}$. & n.a. & n.a. & -100 & -116 & -120 & -103 & n.a. \\
\hline $\begin{array}{c}\delta^{65} \mathrm{Cu}_{\mathrm{N}} \\
\text { IST } 976\end{array}$ & 2 & 1.00 & 13.64 & 5.64 & 13.31 & n.a. & n.a. & n.a. & n.a. & 1.11 \\
\hline
\end{tabular}

${ }^{\mathrm{a}}$ n.d. $=$ not detected

${ }^{\mathrm{b}}$ calculated by difference

${ }^{\mathrm{c}}$ n.a. $=$ not analyzed 
Table 3. Hydrogen isotopes instrumental mass fractionation for turquoise standards.

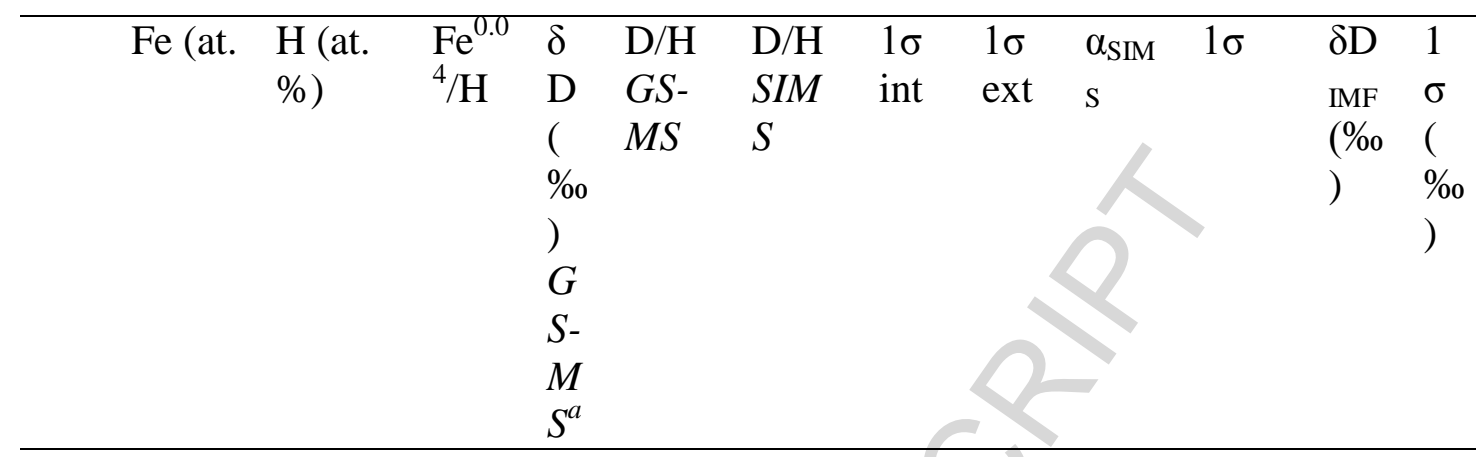

Mar 272013

$\begin{array}{llllllllllllr} & & & & & - & 1.43 & 6.00 & 1.8 & 2.2 & & & - \\ \text { SB } & 0.16 & 21.35 & 0.04 & 7 & 92 \mathrm{E}- & 80 \mathrm{E}- & 0 \mathrm{E}- & 4 \mathrm{E}- & 0.41 & 1.56 & 58\end{array}$



$\begin{array}{lllllll}\mathrm{K} & 1 & 1.40 & 6.09 & 1.8 & 3.9\end{array}$

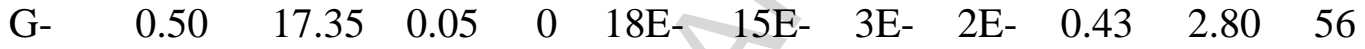

$\begin{array}{lllllllllllll}1 & (0.04) & (1.36) & 61 & 0 & 04 & 05 & 07 & 07 & 453 & \mathrm{E}-03 & 5 & 3\end{array}$

$\begin{array}{lllllll}\mathrm{R} & 1 & 1.37 & 5.82 & 1.8 & 4.4\end{array}$

$\begin{array}{llllllllllll}\mathrm{Y}- & 0.56 & 18.46 & 0.05 & 1 & 69 \mathrm{E}- & 42 \mathrm{E}- & 9 \mathrm{E}- & 6 \mathrm{E}- & 0.42 & 3.24 & 57\end{array}$

$\begin{array}{lllllllllllll}1 & (0.03) & (0.77) & 29 & 6 & 04 & 05 & 07 & 07 & 298 & \mathrm{E}-03 & 7 & 3\end{array}$

$\begin{array}{llllllllllll}\text { R } & & & & 1 & 1.37 & 5.75 & 1.8 & 2.8 & & & - \\ \mathrm{Y}- & 0.78 & 19.52 & 0.05 & 2 & 07 \mathrm{E}- & 34 \mathrm{E}- & 7 \mathrm{E}- & 9 \mathrm{E}- & 0.41 & 2.11 & 58\end{array}$

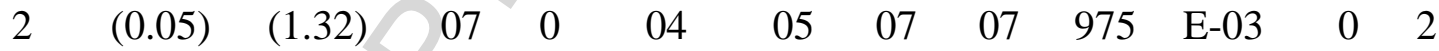

$\begin{array}{lrrrrrrrrrrrr} & & & & 1 & 1.39 & 5.89 & 2.3 & 3.2 & & & \\ \mathrm{CS} & 3.43 & 20.03 & 0.05 & 0 & 72 \mathrm{E}- & 18 \mathrm{E}- & 6 \mathrm{E}- & 4 \mathrm{E}- & 0.42 & 2.32 & 57 & \\ -1 & (0.19) & (1.24) & 24 & 3 & 04 & 05 & 07 & 07 & 170 & \mathrm{E}-03 & 8 & 2\end{array}$

Mar 282013

$\begin{array}{lrrrrrrrrrrrrr} & & & & - & 1.43 & 6.08 & 1.8 & 2.5 & & & - & \\ \text { SB } & 0.16 & 21.35 & 0.04 & 7 & 92 \mathrm{E}- & 54 \mathrm{E}- & 3 \mathrm{E}- & 5 \mathrm{E}- & 0.42 & 1.77 & 57 & \\ -1 & (0.01) & (1.01) & 35 & 6 & 04 & 05 & 07 & 07 & 282 & \mathrm{E}-03 & 7 & 2 \\ & & & & - & & & & & & & & \\ \mathrm{K} & & & & 1 & 1.40 & 6.18 & 1.8 & 3.3 & & & - & \\ \text { G- } & 0.50 & 17.35 & 0.05 & 0 & 18 \mathrm{E}- & 87 \mathrm{E}- & 6 \mathrm{E}- & 0 \mathrm{E}- & 0.44 & 2.35 & 55 & \\ 1 & (0.04) & (1.36) & 61 & 0 & 04 & 05 & 07 & 07 & 147 & \mathrm{E}-03 & 9 & 2 \\ & & & & - & & & & & & & & \\ \mathrm{R} & & & & 1 & 1.37 & 5.90 & 1.7 & 3.9 & & & - & \\ \mathrm{Y}- & 0.56 & 18.46 & 0.05 & 1 & 69 \mathrm{E}- & 88 \mathrm{E}- & 7 \mathrm{E}- & 6 \mathrm{E}- & 0.42 & 2.88 & 57 & \\ 1 & (0.03) & (0.77) & 29 & 6 & 04 & 05 & 07 & 07 & 913 & \mathrm{E}-03 & 1 & 3 \\ & & & & - & & & & & & & & \\ \mathrm{R} & & & & 1 & 1.37 & 5.85 & 1.7 & 2.3 & & & - & \\ \mathrm{Y}- & 0.78 & 19.52 & 0.05 & 2 & 07 \mathrm{E}- & 17 \mathrm{E}- & 6 \mathrm{E}- & 2 \mathrm{E}- & 0.42 & 1.70 & 57 & \\ 2 & (0.05) & (1.32) & 07 & 0 & 04 & 05 & 07 & 07 & 692 & \mathrm{E}-03 & 3 & 2 \\ \mathrm{CS} & 3.43 & 20.03 & 0.05 & - & 1.39 & 6.03 & 1.8 & 6.0 & 0.43 & 4.30 & - & \\ -1 & (0.19) & (1.24) & 24 & 1 & 72 \mathrm{E}- & 31 \mathrm{E}- & 1 \mathrm{E}- & 0 \mathrm{E}- & 181 & \mathrm{E}-03 & 56 & 4\end{array}$


Mar 302013

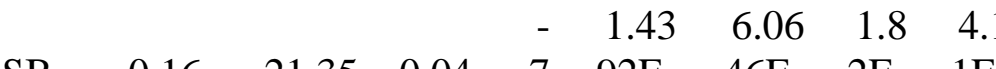

$\begin{array}{llllllllllll}\mathrm{SB} & 0.16 & 21.35 & 0.04 & 7 & 92 \mathrm{E}- & 46 \mathrm{E}- & 2 \mathrm{E}- & 1 \mathrm{E}- & 0.42 & 2.86 & 57\end{array}$

$\begin{array}{lllllllllllll}-1 & (0.01) & (1.01) & 35 & 6 & 04 & 05 & 07 & 07 & 138 & \mathrm{E}-03 & 9 & 3\end{array}$

$\begin{array}{llllll}\mathrm{K} & 1 & 1.40 & 6.12 & 1.8 & 3.9\end{array}$

$\begin{array}{llllllllllll}\text { G- } & 0.50 & 17.35 & 0.05 & 0 & 18 \mathrm{E}- & 04 \mathrm{E}- & 4 \mathrm{E}- & 6 \mathrm{E}- & 0.43 & 2.82 & 56\end{array}$

$\begin{array}{lllllllllllll}1 & (0.04) & (1.36) & 61 & 0 & 04 & 05 & 07 & 07 & 660 & \mathrm{E}-03 & 3 & 3\end{array}$

$\begin{array}{lllllll}\mathrm{R} & & 1 & 1.37 & 5.82 & 2.0 & 1.3\end{array}$

$\begin{array}{llllllllllll}\text { Y- } & 0.56 & 18.46 & 0.05 & 1 & 69 \mathrm{E}- & 71 \mathrm{E}- & 4 \mathrm{E}- & 7 \mathrm{E}- & 0.42 & 9.97 & 57\end{array}$



$\begin{array}{llllll}\mathrm{R} & 1 & 1.37 & 5.78 & 2.1 & 3.5\end{array}$

$\begin{array}{llllllllllll}\text { Y- } & 0.78 & 19.52 & 0.05 & 2 & 07 \mathrm{E}- & 17 \mathrm{E}- & 7 \mathrm{E}- & 2 \mathrm{E}- & 0.42 & 2.57 & 57\end{array}$

$\begin{array}{lllllllllllll}2 & (0.05) & (1.32) & 07 & 0 & 04 & 05 & 07 & 07 & 181 & \mathrm{E}-03 & 8 & 3\end{array}$

\begin{tabular}{lllllllllllll}
-1 & $(0.19)$ & $(1.24)$ & 24 & 3 & 04 & 05 & 07 & 07 & 815 & $\mathrm{E}-03$ & 2 & 3 \\
\hline
\end{tabular}

${ }^{\mathrm{a}}$ error of GS-MS analyses $=1 \%$ o $(1 \sigma)$ 
Table 4. Copper isotopes instrumental mass fractionation for turquoise standards.

\begin{tabular}{|c|c|c|c|c|c|c|c|c|c|c|c|c|}
\hline & $\begin{array}{l}\mathrm{Fe} \text { (at. } \\
\% \text { ) }\end{array}$ & $\begin{array}{l}\log ( \\
\mathrm{Fe})\end{array}$ & $\begin{array}{l}\delta^{65} \\
\mathrm{Cu} \\
(\% o \\
) \\
I C \\
P- \\
M S\end{array}$ & $\begin{array}{l}1 \sigma \\
( \\
\% \text { o } \\
)\end{array}$ & $\begin{array}{l}{ }^{65} \mathrm{Cu} / \\
{ }^{63} \mathrm{Cu} \\
I C P- \\
M S\end{array}$ & $\begin{array}{l}{ }^{65} \mathrm{Cu} / \\
{ }^{63} \mathrm{Cu} \\
\text { SIMS }\end{array}$ & $\begin{array}{l}1 \sigma \\
\text { int }\end{array}$ & $\begin{array}{l}1 \sigma \\
\text { ext }\end{array}$ & $\begin{array}{l}\alpha_{\mathrm{SIM}} \\
\mathrm{S}\end{array}$ & $1 \sigma$ & $\begin{array}{l}\delta^{65} \mathrm{C} \\
\mathrm{u}_{\mathrm{IMF}} \\
(\% \mathrm{o})\end{array}$ & $\begin{array}{l}1 \\
\sigma \\
( \\
\% o \\
)\end{array}$ \\
\hline \multicolumn{13}{|c|}{ Feb $\longdiv { 1 2 2 0 1 3 }$} \\
\hline VG & 0.10 & - & 2.1 & 0. & 0.446 & 0.437 & $5 \mathrm{E}-$ & $1 \mathrm{E}-$ & 0.97 & 2.71 & - & 0. \\
\hline-1 & $(0.01)$ & 1.00 & 0 & 04 & 57 & 54 & $\begin{array}{l}04 \\
1.7\end{array}$ & & 979 & E-04 & 20.2 & 3 \\
\hline $\begin{array}{l}\text { SB- } \\
1\end{array}$ & $\begin{array}{l}0.16 \\
(0.01)\end{array}$ & $-\overline{0.79}$ & $\begin{array}{l}7.3 \\
0\end{array}$ & $\begin{array}{l}0 . \\
07\end{array}$ & $\begin{array}{l}0.448 \\
88\end{array}$ & $\begin{array}{l}0.440 \\
32\end{array}$ & $\begin{array}{l}6 \mathrm{E}- \\
04 \\
1.7\end{array}$ & $\begin{array}{l}5 \mathrm{E}- \\
04 \\
1.7\end{array}$ & $\begin{array}{l}0.98 \\
092\end{array}$ & $\begin{array}{l}2.34 \\
\text { E-04 }\end{array}$ & $\begin{array}{l}- \\
19.1\end{array}$ & $\begin{array}{l}0 . \\
2\end{array}$ \\
\hline KM & $\begin{array}{l}0.27 \\
(0.01)\end{array}$ & $\begin{array}{l}- \\
0.58\end{array}$ & $\begin{array}{l}1.8 \\
6\end{array}$ & $\begin{array}{l}0 . \\
01\end{array}$ & $\begin{array}{l}0.446 \\
46\end{array}$ & $\begin{array}{l}0.438 \\
12\end{array}$ & $\begin{array}{l}5 \mathrm{E}- \\
04 \\
1.7\end{array}$ & $\begin{array}{l}6 \mathrm{E}- \\
04 \\
1.7\end{array}$ & $\begin{array}{l}0.98 \\
131\end{array}$ & $\begin{array}{l}3.94 \\
\text { E-04 }\end{array}$ & $\begin{array}{l}- \\
18.7\end{array}$ & $\begin{array}{l}0 . \\
4\end{array}$ \\
\hline $\mathrm{EC}$ & $\begin{array}{l}0.41 \\
(0.02)\end{array}$ & $\begin{array}{l}- \\
0.39\end{array}$ & $\begin{array}{l}5.6 \\
4\end{array}$ & $\begin{array}{l}0 . \\
01\end{array}$ & 0.448 & $\begin{array}{l}0.440 \\
11\end{array}$ & $\begin{array}{l}6 \mathrm{E}- \\
04 \\
1.4\end{array}$ & $\begin{array}{l}3 \mathrm{E}- \\
04 \\
1.8\end{array}$ & $\begin{array}{l}0.98 \\
207\end{array}$ & $\begin{array}{l}3.86 \\
\text { E-04 }\end{array}$ & $\begin{array}{l}- \\
17.9\end{array}$ & $\begin{array}{l}0 . \\
4\end{array}$ \\
\hline $\begin{array}{l}\text { CA } \\
\text { S-1 }\end{array}$ & $\begin{array}{l}6.49 \\
(0.58)\end{array}$ & 0.81 & $\begin{array}{l}1.1 \\
1\end{array}$ & $\begin{array}{l}0 . \\
02\end{array}$ & $\begin{array}{l}0.446 \\
12\end{array}$ & $\begin{array}{l}0.439 \\
73\end{array}$ & $\begin{array}{l}1 \mathrm{E}- \\
04\end{array}$ & $\begin{array}{l}7 \mathrm{E}- \\
04\end{array}$ & $\begin{array}{l}0.98 \\
567\end{array}$ & $\begin{array}{l}4.19 \\
\text { E-04 }\end{array}$ & $\begin{array}{l}- \\
14.3\end{array}$ & $\begin{array}{l}0 . \\
4\end{array}$ \\
\hline
\end{tabular}

Feb 132013

$\begin{array}{llllllllllllll}\text { VG } & 0.10 & - & 2.1 & 0 . & 0.446 & 0.437 & 5 \mathrm{E}- & 9 \mathrm{E}- & 0.97 & 3.79 & - & 0 . \\ -1 & (0.01) & 1.00 & 0 & 04 & 57 & 51 & 04 & 04 & 971 & \mathrm{E}-04 & 20.3 & 4 \\ & & & & & & & 1.7 & 1.8 & & & & \\ \text { SB- } & 0.16 & - & 7.3 & 0 . & 0.448 & 0.440 & 6 \mathrm{E}- & 3 \mathrm{E}- & 0.98 & 4.07 & - & 0 . \\ 1 & (0.01) & 0.79 & 0 & 07 & 88 & 36 & 04 & 04 & 102 & \mathrm{E}-04 & 19.0 & 4 \\ & & & & & & & 1.7 & 7.6 & & & & \\ & 0.27 & - & 1.8 & 0 . & 0.446 & 0.438 & 5 \mathrm{E}- & 5 \mathrm{E}- & 0.98 & 1.71 & - & 0 . \\ \mathrm{KM} & (0.01) & 0.58 & 6 & 01 & 46 & 07 & 04 & 05 & 121 & \mathrm{E}-04 & 18.8 & 2 \\ & & & & & & & 1.7 & 1.1 & & & & \\ & 0.41 & - & 5.6 & 0 . & 0.448 & 0.439 & 6 \mathrm{E}- & 6 \mathrm{E}- & 0.98 & 2.60 & - & 0 . \\ \mathrm{EC} & (0.02) & 0.39 & 4 & 01 & 14 & 93 & 04 & 04 & 167 & \mathrm{E}-04 & 18.3 & 3 \\ & & & & & & & 1.3 & 3.8 & & & & \\ \mathrm{CA} & 6.49 & & 1.1 & 0 . & 0.446 & 0.439 & 2 \mathrm{E}- & 2 \mathrm{E}- & 0.98 & 8.57 & - & 0 . \\ \mathrm{S}-1 & (0.58) & 0.81 & 1 & 02 & 12 & 82 & 04 & 05 & 587 & \mathrm{E}-05 & 14.1 & 1\end{array}$

Feb 232013

$\begin{array}{lllllllllllll}\text { VG } & 0.10 & - & 2.1 & 0 . & 0.446 & 0.436 & 5 \mathrm{E}- & 7 \mathrm{E}- & 0.97 & 3.30 & - & 0 . \\ -1 & (0.01) & 1.00 & 0 & 04 & 57 & 84 & 04 & 04 & 822 & \text { E-04 } & 21.8 & 3 \\ \text { SB- } & 0.16 & - & 7.3 & 0 . & 0.448 & 0.439 & 1.7 & 1.7 & 0.97 & 3.87 & - & 0 . \\ 1 & (0.01) & 0.79 & 0 & 07 & 88 & 63 & 6 \mathrm{E}- & 4 \mathrm{E}- & 938 & \mathrm{E}-04 & 20.6 & 4\end{array}$




\begin{tabular}{lllllllllllllll} 
& & & & \multicolumn{1}{c}{04} & 04 & & & & \\
& & 0.27 & - & 1.8 & 0. & 0.446 & 0.437 & $5 \mathrm{E}-$ & $7 \mathrm{E}-$ & 0.97 & 2.14 & - & 0. \\
$\mathrm{KM}$ & $(0.01)$ & 0.58 & 6 & 01 & 46 & 39 & 04 & 05 & 968 & $\mathrm{E}-04$ & 20.3 & 2 \\
& & & & & & & 1.7 & 1.7 & & & & \\
& 0.41 & - & 5.6 & 0. & 0.448 & 0.439 & $6 \mathrm{E}-$ & $2 \mathrm{E}-$ & 0.98 & 3.84 & - & 0. \\
$\mathrm{EC}$ & $(0.02)$ & 0.39 & 4 & 01 & 14 & 36 & 04 & 04 & 040 & $\mathrm{E}-04$ & 19.6 & 4 \\
& & & & & & & 1.4 & 1.6 & & & & \\
$\mathrm{CA}$ & 6.49 & & 1.1 & 0. & 0.446 & 0.439 & $1 \mathrm{E}-$ & $6 \mathrm{E}-$ & 0.98 & 3.72 & - & 0. \\
$\mathrm{~S}-1$ & $(0.58)$ & 0.81 & 1 & 02 & 12 & 12 & 04 & 04 & 429 & $\mathrm{E}-04$ & 15.7 & 4 \\
\hline
\end{tabular}


Table 5. Coefficients $a, b$ and $c$ and $\mathrm{R}^{2}$ values for the fit $\delta \mathrm{D}_{\mathrm{IMF}}=a \exp \left(b \mathrm{Fe}^{0.04} / \mathrm{H}\right)+c$, with $\mathrm{Fe}$ and $\mathrm{H}$ in at. $\%$.

\begin{tabular}{lcccc}
\hline Session & $a$ & $b$ & $c$ & $\mathrm{R}^{2}$ \\
\hline Mar 27 2013 & $2.373610^{-8}$ & 364.08 & -582.76 & 0.99952 \\
Mar 28 2013 & $1.549110^{-5}$ & 250.48 & -577.98 & 0.96522 \\
Mar 30 2013 & $3.386510^{-9}$ & 396.83 & -578.9 & 0.88843 \\
\hline
\end{tabular}


Table 6. Comparison between GS-MS and SIMS hydrogen isotopic results for turquoise standards.

\begin{tabular}{|c|c|c|c|c|c|c|c|c|}
\hline & $\begin{array}{l}\delta D_{\text {GS-MS }} \\
(\%)\end{array}$ & $\begin{array}{l}1 \sigma \\
(\% 0)\end{array}$ & $\begin{array}{l}\delta D_{\text {SIMS }^{\mathrm{a}}}(\%) \\
\operatorname{Mar} 27 \\
2013\end{array}$ & $\begin{array}{l}1 \sigma \\
(\%)\end{array}$ & $\begin{array}{l}\delta \mathrm{D}_{\mathrm{SIMS}}^{\mathrm{a}}(\%) \\
\operatorname{Mar} 28 \\
2013\end{array}$ & $\begin{array}{l}1 \sigma \\
(\% 0)\end{array}$ & $\begin{array}{l}\delta \mathrm{D}_{\mathrm{SIMS}}^{\mathrm{a}}(\%) \\
\operatorname{Mar} 30 \\
2013\end{array}$ & $\begin{array}{l}1 \sigma \\
(\%)\end{array}$ \\
\hline SB-1 & -76 & & -76 & 3 & -76 & 4 & -76 & 6 \\
\hline KG-1 & -100 & & -100 & 6 & -100 & 5 & -100 & 6 \\
\hline RY-1 & -116 & & -116 & 7 & -120 & & -121 & 2 \\
\hline RY-2 & -120 & & -120 & 4 & -120 & 3 & -122 & 5 \\
\hline CS-1 & -103 & & -103 & 5 & -99 & 9 & -96 & 6 \\
\hline
\end{tabular}

${ }^{\text {a }}$ Calculated using the correction schemes given in Table 5 
Table 7. Coefficients $a$ and $b$ and $\mathrm{R}^{2}$ values for the linear regression $\delta^{65} \mathrm{Cu}_{\mathrm{IMF}}=$ $a \log (\mathrm{Fe})+b$, with $\mathrm{Fe}$ in at. $\%$.

\begin{tabular}{lccc}
\hline Session & $a$ & $b$ & $\mathrm{R}^{2}$ \\
\hline Feb 12 2013 & 3.1425 & -16.825 & 0.9929 \\
Feb 13 2013 & 3.2738 & -16.828 & 0.9864 \\
Feb 23 2013 & 3.2541 & -18.342 & 0.9934
\end{tabular}


Table 8. Comparison between ICP-MS and SIMS copper isotopic results for turquoise standards.

\begin{tabular}{|c|c|c|c|c|c|c|c|c|}
\hline & $\begin{array}{l}\delta^{65} \mathrm{Cu}_{\mathrm{ICP}-\mathrm{MS}} \\
(\% \mathrm{o})\end{array}$ & $\begin{array}{l}1 \sigma \\
(\%)\end{array}$ & $\begin{array}{l}\delta^{65} \mathrm{Cu}_{\text {SIMS }}{ }^{a} \\
(\%) \\
\text { Feb } 12 \\
2013\end{array}$ & $\begin{array}{l}1 \sigma \\
(\%)\end{array}$ & $\begin{array}{l}\delta^{65} \mathrm{Cu}_{\text {SIMS }}{ }^{\mathrm{a}} \\
(\% \mathrm{o}) \\
\text { Feb } 13 \\
2013\end{array}$ & $\begin{array}{l}1 \sigma \\
(\%)\end{array}$ & $\begin{array}{l}\delta^{65} \mathrm{Cu}_{\text {SIMS }}{ }^{\mathrm{a}} \\
(\% \text { o) } \\
\text { Feb } 23 \\
2013\end{array}$ & $\begin{array}{l}1 \sigma \\
(\%)\end{array}$ \\
\hline VG-1 & 2.10 & 0.04 & 1.8 & 0.3 & 1.9 & 0.4 & 1.9 & 0.3 \\
\hline SB-1 & 7.30 & 0.07 & 7.5 & 0.2 & 7.8 & 0.4 & 7.6 & 0.4 \\
\hline KM & 1.86 & 0.01 & 1.8 & 0.4 & 1.8 & 0.2 & 1.7 & 0.2 \\
\hline $\mathrm{EC}$ & 5.64 & 0.01 & 5.8 & 0.4 & 5.4 & 0.3 & 5.7 & 0.4 \\
\hline CAS-1 & 1.11 & 0.02 & 1.0 & 0.4 & 1.2 & 0.1 & 1.1 & 0.4 \\
\hline
\end{tabular}

${ }^{\text {a }}$ Calculated using the correction schemes given in Table 7 